\title{
PROJEÇÕES DE MUDANÇAS NA PRECIPITAÇÃO E TEMPERATURA NO NORDESTE BRASILEIRO UTILIZANDO A TÉCNICA DE DOWNSCALING DINÂMICO
}

\author{
DOMINGO CASSAIN SALES ${ }^{1,2}$, ALEXANDRE ARAÚJO COSTA ${ }^{1}$, EMERSON MARIANO DA SILVA ${ }^{1}$, \\ FRANCISCO DAS CHAGAS VASCONCELOS JÚNIOR ${ }^{3}$, ARNÓBIO DE MENDONÇA BARRETO \\ CAVALCANTE $^{2}$, SALOMÃO DE SOUSA MEDEIROS ${ }^{2}$, ALDRIN MARTIN PEREZ MARIN ${ }^{2}$, \\ SULLYANDRO OLIVEIRA GUIMARÃES ${ }^{1}$, LUIZ MARTINS DE ARAÚJO JUNIOR ${ }^{4}$, \\ JOSÉ MARCELO RODRIGUES PEREIRA ${ }^{3}$
}

${ }^{1}$ Universidade Estadual do Ceará (UECE), Programa de Pós-graduação em Ciências Físicas Aplicadas (CMACFA), Fortaleza, CE, Brasil

${ }^{2}$ Instituto Nacional do Semiárido (INSA), Campina Grande, PB, Brasil

${ }^{3}$ Fundação Cearense de Meteorologia e Recursos Hídricos (FUNCEME), Fortaleza, CE, Brasil

${ }^{4}$ Universidade Federal do Ceará (UFC), Programa de Engenharia Civil, Departamento de Engenharia Hidráulica e Ambiental (POSDEHA), Fortaleza, CE, Brasil

domingosales@gmail.com, alexandrearaujoc@gmail.com, emerson.mariano@uece.br, sullyandro@gmail. com,arnobio@insa.gov.br, salomao@insa.gov.br, aldrin@insa.gov.br,juniorphy@gmail.com, lu.m.a.junior@gmail.com, marcelorodriguesss@gmail.com

Recebido Maio de 2014 - Aceito Abril de 2015

\section{RESUMO}

Este trabalho apresenta análises de projeções de mudanças nos campos de precipitação e temperatura em simulações de downscaling dinâmico no contexto do projeto CORDEX. O domínio da simulação corresponde às Américas Tropicais, mas a região de estudo se restringe a duas sub-regiões do Nordeste Brasileiro: Norte (NNEB) e Sul (SNEB). O modelo regional utilizado nas simulações foi o RAMS6.0, forçado por dados do modelo global HadGEM2-ES. Foram analisados os períodos presente e três "fatias de tempo" futuras sob o cenário climático RCP8.5. Para a precipitação e temperatura no clima presente, a simulação foi comparada com os dados do CRU com finalidade de avaliar o desempenho e os erros de viés dos modelos. O RAMS6.0 mostra-se superior ao HadGEM2-ES em aspectos como, a representação da fase do ciclo anual de precipitação e temperatura, redução do viés seco na estação seca sobre o NNEB e distribuição espacial de ambas as variáveis, especialmente temperatura. Entretanto, o RAMS6.0 também exacerba alguns erros do modelo global, como o viés úmido na estação chuvosa. No clima futuro, foram analisadas as mudanças nos valores climatológicos e nos campos anuais das duas variáveis. Alguns padrões projetados pelos dois modelos incluem redução da precipitação no inverno austral e aumento da temperatura no decorrer do século.

Palavras-chave: Mudanças Climáticas; CORDEX; Ciclo Anual.

\begin{abstract}
PROJECTIONS OF PRECIPITATION AND TEMPERATURE CHANGES OVER NORTHEAST BRAZIL USING THE DYNAMICAL DOWNSCALING TECHNIQUE

This paper presents analysis of projected changes on precipitation and temperature perfomed by dynamical downscaling simulations in the CORDEX Project context. The simulation domain encompasses the Tropical Americas but the focus of this study is restricted to the Northeast Brazil subregions: North (NNEB) and South (SNEB). The regional model run in the simulations was RAMS6.0, forced by HadGEM2-ES global model data. The present period and three future time slices under the RCP8.5 climate scenario were analyzed. Current precipitation and temperature were compared against CRU observed data, to evaluate the performance and the biases from the regional and the global model. In comparison to the HadGEM2-ES model, RAMS6.0 is superior in some
\end{abstract}


aspects as the phase representation of the annual precipitation and temperature cycle, reduction of the dry bias during the dry season over the NNEB and spatial distribution of the two variables, especially temperature. However, RAMS6.0 exacerbates some errors from the global model, like the wet bias in the rainy season. In the future climate, changes in the climatological value and annual mean fields of both variables were analyzed. Some patterns were projected by both models, like decreasing precipitation during austral winter and increasing temperature throughout the century.

Keywords: Climate Change, CORDEX, Annual Cycle.

\section{INTRODUÇÃO}

O quarto e o quinto Relatório de Avaliação do Intergovernmental Panel on Climate Change (IPCC), Assessment Report Fourth (AR4 - IPCC, 2007) e Assessment Report Fifth (AR5 - IPCC, 2013), respectivamente, trouxeram novas e fortes evidências que o sistema energético utilizado pela sociedade atual baseado, em parte, na queima de combustíveis fósseis, terá impactos significativos sobre o clima em virtude do acúmulo de gases de efeito estufa (principalmente dióxido de carbono) na atmosfera, influenciando os padrões futuros de temperatura e precipitação em todo o globo. Essas modificações podem acarretar sérios problemas em regiões vulneráveis, particularmente em setores como agricultura e recursos hídricos, os quais já sofrem impactos da variação climática natural, e podem ter o quadro agravado em um clima mais quente e com possíveis mudanças nos padrões de chuva regional.

Uma dessas regiões é o Nordeste do Brasil (NEB), que abriga a maior parte do semiárido brasileiro. Nela, verificam-se três regimes climáticos com distribuições pluviométricas diferentes: o norte do NEB (com precipitação máxima em março dominada pela atuação da Zona de Convergência Intertropical - ZCIT), o litorâneo úmido, ocorrendo na costa leste, com precipitação máxima em maio, e o do sul do NEB, com precipitação máxima em dezembro (Kousky, 1979; Kayano e Andreoli, 2009). O sertão nordestino sofre pela irregularidade espacial e temporal das chuvas e pela ocorrência de seca ou estiagem, dificultando, assim, o desenvolvimento local das atividades agropecuárias, tornando importante conhecer as possibilidades de mudanças no clima, principalmente para os campos de precipitação e temperatura.

Uma das ferramentas que auxilia a análise das possíveis mudanças climáticas em uma determinada região ou em padrões globais são os modelos climáticos. Estes incluem Modelos Climáticos Globais (MCG), que, por limitações computacionais, possuem resolução espacial horizontal de centenas de quilômetros, não sendo capazes de resolver fenômenos atmosféricos em escalas menores, como fenômenos de mesoescala e locais; e Modelos Climáticos Regionais (MCR), que possuem um domínio limitado e resolução espacial na ordem de dezenas de quilômetros que permitem enxergar e resolver características do sistema terrestre não observada nos MCG, por exemplo, topografia, linha de costa, vegetação heterogênea, sistema de brisa e outros.

Vale ressaltar que, em alguns centros de pesquisa, a utilização de MCG de alta resolução espacial (da ordem de dezenas de quilômetros) já é uma realidade, um exemplo é o modelo global de previsão de tempo do Met Office, com espaçamento de grade de $17 \mathrm{~km}$ em latitudes médias (Met Office, 2014) e o modelo de previsão de tempo do NCEP (National Centers for Environmental Prediction), o GFS (Global Forecast System), com $28 \mathrm{~km}$ de espaçamento de grade (NCDC NOAA, 2014). Porém, o mesmo não pode ser dito para a maioria dos centros de modelagem que realizaram simulações para ajudar a construir os relatórios de avaliação do IPCC. No AR4, o modelo de menor espaçamento de grade foi o MIROC3.2(hires), com aproximadamente $1,1^{\circ}$. No AR5, os modelos CMCC-CM e MIROC4h são os únicos que possuem espaçamento abaixo de $1^{\circ}$ tanto na latitude e longitude, $0,75^{\circ} \times 0,75^{\circ}$ e $0,5625^{\circ} \times 0,5625^{\circ}$, respectivamente (IPCC,2007; IPCC, 2013).

Para uma maior confiabilidade, os estudos de mudanças climáticas requerem uma padronização dos experimentos de modelagem a serem realizados. Com esse intuito, surgiu o CMIP (Coupled Models Intercomparison Project), que em sua terceira fase (CMIP3) subsidiou o AR4 e o CMIP5, o AR5 (Taylor et al., 2012). Para o AR5, novos cenários de concentração de Gases de Efeito Estufa (GEE) foram utilizados, os chamados RCP (do inglês Representative Concentration Pathways, Moss et al., 2010), substituindo aqueles utilizados no AR4, os cenários do SRES (Special Report on Emission Scenarios, Nakicenovic et al., 2010).

Cada RCP foi desenvolvido por um grupo de cenarização diferente e recebem seus nomes a partir das forçantes radiativas durante o século XXI. RCP 3-PD (Peak and Decline) indica uma forçante de pico, em meados do século, em $3 \mathrm{~W} / \mathrm{m}^{2}$ e depois decai para 2,6 W/m² até 2100 (podendo ser chamado também de RCP2.6). O segundo cenário definido como RCP 4.5 indica uma estabilização em $4,5 \mathrm{~W} / \mathrm{m}^{2}$ antes do final do século XXI. Já o RCP 6.0 indica uma estabilização em $6 \mathrm{~W} / \mathrm{m}^{2}$ após 2100. Por fim o cenário com mais altas concentrações de GEE, o RCP 8.5 apresenta estabilização de $12 \mathrm{~W} / \mathrm{m}^{2}$ após o final do século, atingindo a forçante radiativa de 8,5 W/m² em 2100. As estimativas de tais forçantes são baseadas nos GEE e outros agentes, contundo não inclui os impactos diretos do uso do solo 
(o que normalmente modifica o albedo) ou a contribuição da poeira mineral, e servem de informação básica a ser utilizada pelos MCG do CMIP5 (RCP Database, 2009).

Para estudos de mitigação e adaptação, faz-se necessário o uso de informações em escala regional e local, que não é alcançada por MCGs. Assim, são necessárias técnicas de regionalização das análises geradas pelos MCGs, como o downscaling dinâmico, no qual os resultados servem de entrada para forçar um MCR. Wang et al. (2004) citam vários estudos que demonstram que, quando fornecidas condições de grande escala apropriadas, como análises globais, MCRs simulam realisticamente características climáticas regionais: precipitação orográfica, eventos climáticos extremos, variações sazonais e diurnas da precipitação e anomalias climáticas de escala regional tais como aquelas associadas com o ENSO (El Niño - Southern Oscillation).

Assim como no CMIP, que uniformiza os experimentos de simulação usando MCGs, grupos de modelagem regional seguem a metodologia proposta pelo CORDEX (Coordinated Regional Climate Downscaling Experiment, Giorgi et al., 2009), o qual fornece uma referência para avaliação de MCRs e propõe um conjunto de experimentos padronizados sobre determinados domínios regionais, cobrindo o conjunto das áreas continentais do planeta. O CORDEX envolve dois conjuntos de simulações: validação dos MCRs, em que estes são forçados por dados do ERA-Interim (Reanálise do ECMWF - European Centre for Medium-Range Weather Forecast), e simulações de projeções climáticas (incluindo as "rodadas históricas", de referência para o clima atual e as simulações do clima futuro), para as quais os MCRs são alimentados por condições de fronteira fornecidas pelos MCGs participantes do CMIP5. O CORDEX prioriza o downscaling dos cenários RCP 4.5 e RCP 8.5 , pois o primeiro é considerado por corresponder ao contexto do "mundo real" no clima presente e ser relevante para os tomadores de decisão (tendo características entre os cenários B1 e A1T, do SRES, utilizados pelo CMIP3/AR4), já o segundo é o cenário de mais altas emissões e é considerado relevante para questões de mitigação (WCRP, 2009).

Diversos trabalhos utilizando a técnica de downscaling dinâmico sobre domínios que incluem o NEB foram realizados. Em estudos de previsão sazonal, Nobre et al. (2001) realizaram a redução de escala em dois níveis sobre o norte da América do Sul, forçando primeiramente o modelo regional RSM (Regional Spectral Model), em um espaçamento de grade de $80 \mathrm{~km}$, com as análises do MCG ECHAM3 e, em seguida, forçando o RSM em um espaçamento de $20 \mathrm{~km}$ com as saídas do RSM80-km. Os autores encontraram que, sobre o NEB, o RSM80-km melhora a previsão de chuvas do MCG enquanto que o RSM20-km apresentou erros maiores, com os padrões espaciais assemelhando-se aos da topografia local.
Sobre a bacia do Atlântico, Sun et al. (2005) aninharam no modelo regional RSM dez membros do AOGCM (GCM com as componentes oceânica e atmosférica acopladas) ECHAM4.5 forçado com Temperatura da Superfície do Mar (TSM) observada. Além de adicionar informação de maior resolução, o RSM corrige parcialmente o deslocamento da ZCIT do Atlântico e representa melhor as anomalias de precipitação sazonais. Dando continuidade ao trabalho anterior, Sun et al. (2006) apresentaram o primeiro sistema de previsão de clima operacional utilizando a técnica de downscaling dinâmico. Os autores encontraram que a habilidade das previsões com escala reduzida é geralmente maior do que as previsões do GCM que as forçaram.

Sobre o domínio da América do Sul, Seth et al. (2007) forçaram o modelo RegCM3 com as condições de fronteiras laterais atmosféricas da reanálise do NCEP/NCAR (National Center for Atmospheric Research) e em seguida por um membro do conjunto de simulações realizadas com o ECHAM4.5 utilizando TSM mensal observada. Sobre o NEB, o modelo regional simula bem o ciclo anual da precipitação e captura muito da variabilidade interanual presente na região. Segundo os autores, é difícil para o modelo regional melhorar características climatológicas de grande escala em regiões onde influências remotas são fortes e o modelo global tem bom desempenho, podendo o RCM degradar a simulação. Já Rauscher et al. (2007) utilizaram o RegCM3 para melhorar as estatísticas de previsão sub-sazonal (intensidade de precipitação diária, início e término da estação chuvosa e frequência e duração dos períodos de seca) de um sistema de previsão experimental. Os resultados de um estudo retrospectivo de 20 anos (estações chuvosas entre janeiro de 1982 a dezembro de 2002) forçando o mesmo com a reanálise do NCEP/NCAR e três membros do conjunto do ECHAM4.5 no domínio da América do Sul, mostraram que, sobre o NEB, o RegCM3 apresentou menores erros que o MCG que o forçou, referente a estação chuvosa (início, duração e término).

Alves e Marengo (2010) forçaram o modelo HadRM3P (Hadley Center Regional Climate Model), do UK Met Office, a partir de três condições iniciais de HadAM3P (atmosférico global do mesmo centro), para avaliar a precisão e habilidade do modelo regional em descrever a variabilidade sazonal das principais características climatológicas da América do Sul. Foi apresentado que o MCR conseguiu resolver os padrões de precipitação e temperatura, bem como os principais padrões de circulação geral, acrescentando informação climática em incluir detalhes capturados pelo HadRM3P em escalas mais finas do que as resolvidas pelo HadAM3P. Porém, os erros sistemáticos encontrados podem estar relacionados com a física do modelo regional e as condições de fronteira laterais e possíveis vieses inseridos do modelo global, como exemplo, o viés frio (quente) no norte (sul) do NEB no verão (inverno) austral. 
No contexto das mudanças climáticas, outros trabalhos de downscaling dinâmico sobre a América do Sul foram realizados. Marengo et al. (2009) analisaram a distribuição de extremos de temperatura e precipitação para o final do século (2071-2100) sob os cenários A2 e B2. Os autores utilizaram o sistema de modelagem climática regional PRECIS (Providing Regional Climates for Impacts Studies) que incorpora o HadRM3P forçado pelo HadAM3P. Para o clima presente (1961-1990), comparado às observações, o modelo simula bem a distribuição espacial dos eventos extremos de temperatura e precipitação. Para as projeções futuras (cenário A2), sobre regiões tropicais, tendências de noites positivas (negativas) para noites quentes (frias) são esperadas. Sobre o NEB e leste da Amazônia, pequena ou nenhuma mudança projetada na intensidade de precipitação são vistas, porém, mudanças significantes na frequência de dias consecutivos secos são esperadas.

Como parte do projeto regional CREAS (Cenários Regionalizados de Clima Futuro sobre a América do Sul), Marengo et al. (2010) apresentaram as projeções do downscaling dinâmico de três modelos regionais (Eta CCS, RegCM3 e HadRM3P) forçados pelo HadAM3P, sob o cenário A2 (2071-2100). Os autores reforçaram a possibilidade do NEB experimentar deficiência de chuvas futuramente. Para a mudança na temperatura, os três modelos projetam aumento, em maior grau na região tropical, chegando a valores entre $6^{\circ}$ e $8^{\circ} \mathrm{C}$ mais quente que o clima presente. Boulanger et al. (2010) apresentaram o projeto CLARIS ("A Europe South America Network for Climate Change Assessment and Impact Studies"), que tem como proposta promover estratégias comuns de pesquisa para observar e prever mudanças climáticas e seus consequentes impactos socioeconômicos na América do Sul. O projeto apresenta três objetivos, sendo um deles o de facilitar a troca de dados climáticos observados e simulados entre os grupos de pesquisa climática, além de criar uma base de dados climáticos de alta qualidade da América do Sul para estudos em eventos extremos e tendências climáticas em longo prazo. Este é um dos projetos coordenados que, juntamente com outros ao redor do mundo, deu origem ao CORDEX.

Reboita et al. (2014) utilizaram o modelo RegCM3 forçado pelos modelos ECHAM5 e HadCM3, sobre o domínio da América do Sul. Foram analisadas as projeções climáticas do futuro próximo (2010-2040, near-future) e distante (20702100, far-future) sob o cenário A1B, comparado ao clima presente (1960-1990). Para o norte da América do Sul são projetadas aquecimento e condições mais secas no verão austral para o futuro distante, chegando a valores acima de $6^{\circ} \mathrm{C}$ no aninhamento do RegCM3 com o HadCM3. O trabalho de revisão de Solman (2013) apresenta os progressos alcançados em atividades de modelagem climática regional sobre a América do Sul. Os desenvolvimentos mais recentes ligados ao downscaling dinâmico tem focado principalmente em fornecer informação de alta resolução sobre mudança climática regional. A autora apresentou esquematicamente áreas, as quais características comuns surgem dos exercícios disponíveis de downscaling, considerando mudanças projetadas para temperatura e precipitação sob o cenário A2 (final do século 21). Sobre o NEB, são destacadas mudanças qualitativas projetadas de aumento (redução) de temperatura (precipitação).

No âmbito do projeto CLARIS-LPB (La Plata Basin) e seguindo o protocolo do CORDEX, Solman et al. (2013) analisaram o desempenho de sete modelos regionais (com espaçamento de grade de $50 \mathrm{~km}$ ) forçado pela reanálise do ERA-Interim sobre a América do Sul no período de 1990 a 2008. A análise teve foco nas médias sazonais, ciclos anuais e distribuições de frequências das médias mensais de precipitação e temperatura do ar superficial. Sobre o NEB, a média dos modelos representa bem o ciclo anual da temperatura, porém com modelos apresentando erros de viés positivo e negativo. Para a precipitação, a maioria dos modelos subestimam as frequências variando de intensidades de precipitação intermediária para intensa, estando em concordância com a subestimação sistemática da precipitação durante a estação chuvosa, apresentada no ciclo anual.

No contexto do projeto CORDEX, foi realizado neste trabalho simulações de downscaling dinâmico, sobre o domínio das Américas Tropicais, utilizando um MCR forçado por um MCG participante do CMIP5. O presente estudo tem como objetivo: (1) analisar e comparar as projeções de mudanças no ciclo anual e nos campos de precipitação e temperatura, em duas regiões do NEB (norte e sul), por parte dos modelos regional e global, (2) identificar a informação adicional que o uso desta técnica apresenta, tanto para o clima presente, como para as projeções do clima futuro e, ainda, (3) comparar os resultados das simulações com as projeções de outros MCGs participantes do CMIP5. A seção 2 apresenta a descrição do MCR utilizado, do MCG que o forçou, do dado observado, das análises dos modelos participantes do CMIP5 e as métricas estatísticas utilizadas. A seção 3 traz os resultados obtidos pelo conjunto de simulações, tanto no período presente, quanto nas projeções futuras e a seção 4 apresenta as considerações finais deste trabalho.

\section{MATERIAIS E MÉTODOS}

\subsection{Modelo regional}

O MCR utilizado neste trabalho foi o RAMS6.0 (Regional Atmospheric Modeling System,version 6, Pielke et al., 1992; Cotton et al., 2003), utilizado operacionalmente para previsão de tempo e clima na FUNCEME (Fundação Cearense de Meteorologia e Recursos Hídricos), como também em 
estudos climáticos para períodos mais longos (Pitman et al., 2007).

A grade do modelo possui 252 por 136 pontos (longitude e latitude, respectivamente) com espaçamento horizontal de 50 $\mathrm{km}$, centrada em $10^{\circ} \mathrm{N} \mathrm{e} 73^{\circ} \mathrm{W}$. A coordenada vertical utilizada é do tipo sigma-z com 29 níveis com espaçamento variando entre 100 metros próximo à superfície e $1,3 \mathrm{~km}$ próximo ao topo do modelo, fazendo com que o mesmo esteja a aproximadamente 20,8km. O domínio da simulação é o das Américas Tropicais (baseado no domínio da América Central do CORDEX) com longitude entre $124,5 \mathrm{~W}$ e $24,5 \mathrm{~W}$ e latitude entre $33,5 \mathrm{~N}$ e $17,5 \mathrm{~S}$ (Figura 1, à esquerda). Este domínio possui uma grande extensão do Oceano Atlântico, bem mais que o domínio da América do Sul, sendo mais adequado o seu uso para resolver a Zona de Convergência Intertropical do Atlântico, a qual é o principal responsável pelas chuvas sobre o NEB.

Os esquemas de parametrização utilizados nas simulações foram: Kain-Fritsch para convecção (Fritsch e Chappell, 1980, Kain e Fritsch, 1990), Chen-Cotton para o fluxo de radiação de onda curta e de onda longa (Chen e Cotton, 1983), Mellor-Yamada para transporte turbulento (Mellor e Yamada, 1974, 1982) e Walko et al. (1995) para microfísica de nuvens. Um relaxamento newtoniano (nudging) foi adotado nas laterais (escala de tempo de 1200s e "zona de buffer" de três pontos), no topo (a partir de 16km, escala de tempo de 43200s) e no domínio inteiro (escala de tempo de 43200s). A escolha da configuração utilizada é justificada pelo trabalho de Sales (2011). Os dados de condição lateral, fornecidas pelo modelo global, são de 6 em 6 horas. Para as condições de contorno inferior, foram utilizados dados diários de TSM simulados pelo HadGEM2-ES. Foram utilizados 11 níveis de solo no modelo regional, todos inicializados com $20 \%$ de umidade, e a mesma é calculada ao longo do tempo pelo modelo LEAF-3 (Land Ecosystem-Atmosphere Feedback, baseado em Walko et al., 2000).

\subsection{Simulações do modelo global}

As análises do MCG utilizadas para forçar o MCR são oriundos do HadGEM2 -ES (Hadley Centre Global Enviromental Model version 2 - Earth System), o qual é um modelo acoplado do sistema terrestre (ESM - Earth System Model). Sua componente atmosférica possui 38 níveis verticais (chegando a cerca de $40 \mathrm{~km}$ de altura) e espaçamento de grade horizontal de aproximadamente $1,875^{\circ}$ por $1,25^{\circ}$, em longitude e latitude respectivamente (192 por 145 pontos de grade). Já a componente oceânica utiliza uma grade horizontal de 360 por 216 pontos (longitude e latitude, respectivamente) com espaçamento de $1^{\circ}$, entre os polos e $30^{\circ}$, refinada gradualmente para $1 / 3$ de $1^{\circ}$ nas proximidades do equador e 40 níveis verticais com espaçamento variável com a altura, com resolução de 10 metros próxima à superfície (Collins et al., 2008).

O esquema de convecção utilizado pelo HadGEM2-ES é baseado no esquema de fluxo de massa de Gregory e Rowntree (1990), porém, com maiores modificações. As convecções profunda e rasa são diagnosticados separadamente, e são aplicados diferentes fechamentos termodinâmicos. Para a convecção rasa, é utilizado o fechamento baseado em Grant (2001), enquanto que para a convecção profunda, um fechamento CAPE (Convective Available Potential Energy) é utilizado, baseado em Fritsch e Chappell (1980). Maiores detalhes sobre a parametrização convectiva utilizada por esse MCG, pode ser encontrado em Martin et al. (2011).

\subsection{Descrição das análises realizadas e dos dados utilizados}

As regiões de estudo são o norte e o sul do Nordeste Brasileiro (NNEB e SNEB, respectivamente), compreendidas entre as longitudes $47 \mathrm{~W}$ e $34,5 \mathrm{~W}$ e as latitudes de $2,5 \mathrm{~S}$ e $10,0 \mathrm{~S}$ para o NNEB e 10S e 16S para o SNEB (Figura 1, à direita).
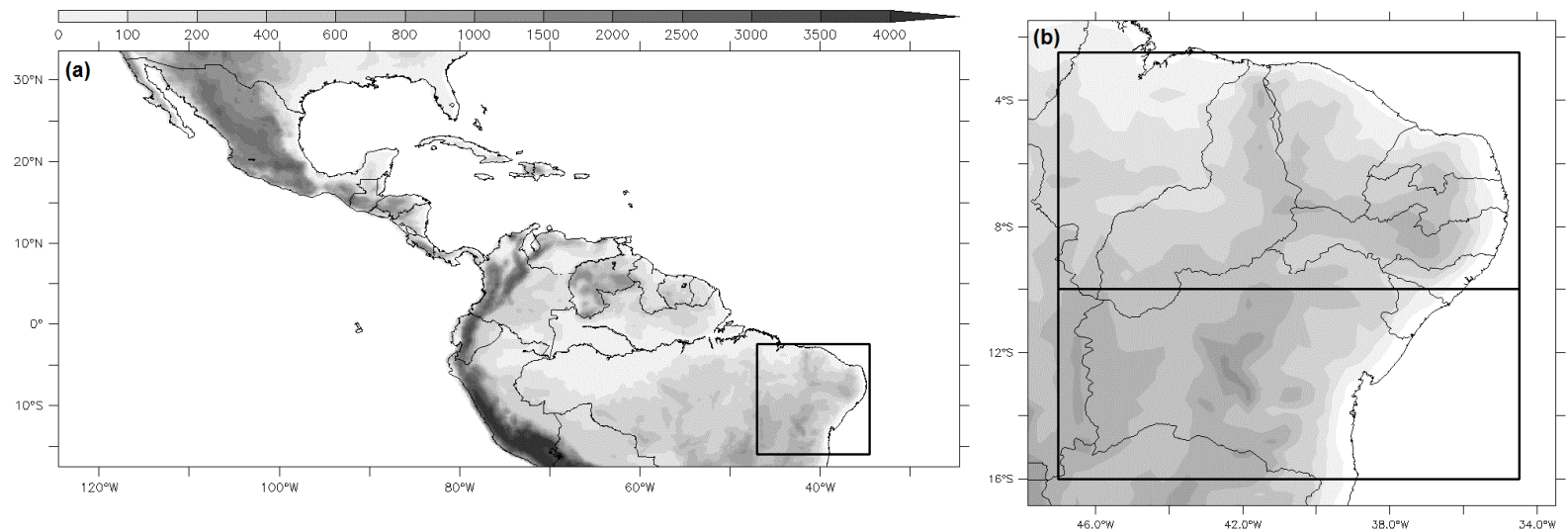

Figura 1 - (a) Domínio das simulações sobre as Américas Tropicais e (b) Nordeste Brasileiro (região de estudo) divido em norte (NNEB) e sul (SNEB). Os níveis representam a altitude, dada em metros. 
Salienta-se que a zona de buffer foi retirada antes de serem feitas as análises, portanto o ruído do relaxamento newtoniano das condições de contorno é minimizado.

Foram analisados períodos de 20 anos de precipitação e temperatura (a $2 \mathrm{~m}$ metros), tanto para o clima presente (1986 a 2005, chamado aqui de "período histórico"), quanto para três "fatias de tempo" (time slices) futuras, sob o cenário RCP 8.5: a de curto (2016 a 2035), médio (2046 a 2065) e longo prazo (2080 a 2099). Para o período histórico, o desempenho do MCR (RAMS6.0) foi comparado ao do MCG (HadGEM2-ES) tomando como dado observado o CRU (Climate Research Unit, New et al., 1999, 2000).

O dado do CRU está disponibilizado em grade de espaçamento de $0,5^{\circ}$ (longitude e latitude) e compreende uma série de variáveis (precipitação e temperatura entre elas) sobre todas as áreas terrestres, incluindo ilhas oceânicas, porém excluindo a Antártida. Para a construção do banco de dados de precipitação (temperatura) em grade, foram utilizados mais de 19000 (12000) normais climatológicas de estações de diversas agências meteorológicas ao redor do mundo. Trabalhos como o de Pesquero et al. (2010) e Solman et al. (2013), utilizaram os dados do CRU em estudos de downscaling dinâmico sobre a América do Sul, com foco em diversas sub-regiões, inclusive o NEB. São utilizadas cerca de 235 (45) estações de precipitação (temperatura) pelo CRU para representar a região de estudo do presente trabalho.

Foram calculados os índices estatísticos de correlação, viés, erro absoluto médio e erro quadrático médio (descritos na Tabela 1), do ciclo anual e das médias sazonais da precipitação e da temperatura, sobre a média espacial das sub-regiões NNEB e SNEB (apenas sobre o continente). Nas equações apresentadas, $\phi$ e $\psi$ representam valores simulados (pelos modelos RAMS6.0 e HadGEM2-ES) e observados (CRU), respectivamente. Além disso, foram gerados os campos médios anuais e sazonais das duas variáveis analisadas a partir dos dados observados e simulados pelos modelos. Para a correlação do ciclo anual (calculadas a partir das médias mensais, possuindo assim 12 amostras), foi aplicado o teste estatístico T de Student com nível de confiança de $5 \%$ para uma distribuição bicaudal (Wilks, 2011). Baseado nesse teste, a correlação crítica é de 0,576.

Para a análise das projeções do clima futuro, foram calculadas as diferenças entre a climatologia das três "fatias de tempo" e a do período histórico, representando mudanças na precipitação (em porcentagem) e temperatura (em graus Celsius), sobre a média espacial das duas sub-regiões (apenas sobre o continente). Em seguida, são apresentados os campos médios anuais da precipitação e temperatura referentes às mudanças a curto, médio e longo prazo simulados por ambos os modelos.

Por último, para comparar e situar as projeções simuladas pelo RAMS6.0 com as dos modelos do CMIP5 (incluindo o HadGEM2-ES), foram feitos os gráficos de distribuição da porcentagem da diferença da precipitação média pela diferença de temperatura média $(\Delta \mathrm{P} / \mathrm{P}$ por $\Delta \mathrm{T})$ para as três "fatias de tempo" futuras em relação ao período histórico, para as sub-regiões estudados neste trabalho. A porcentagem da diferença da precipitação média foi adotada, pois uma mudança de $\mathrm{X} \mathrm{mm}$ na média anual simulada por um modelo (por exemplo, $300 \mathrm{~mm}$ ) pode significar uma pequena (grande) mudança, caso o modelo tenha um viés muito úmido (seco) comparado às observações do clima presente. A Tabela 2 apresenta os 38 modelos do CMIP5 que disponibilizaram suas análises necessárias para a produção deste trabalho.

\section{RESULTADOS E DISCUSSÕES}

\subsection{Período histórico}

A Figura 2 mostra a climatologia da precipitação e temperatura (apenas sobre o continente) no período histórico, simulada pelos modelos RAMS6.0 e HadGEM2-ES, e observada pelo banco de dados do CRU, nas sub-regiões norte

Tabela 1 - Índices estatísticos utilizados no estudo, com seus respectivos símbolos, formulações matemáticas e valores ideais.

\begin{tabular}{cccc}
\hline Índice & Símbolo & Fórmula & $\begin{array}{c}\text { Valor } \\
\text { Ideal }\end{array}$ \\
\hline Correlação & $r$ & $r=\frac{1}{N} \sum_{i=1}^{N} \frac{\phi_{i}^{\prime} \psi_{i}^{\prime}}{\sigma_{\phi} \sigma_{\psi}}$ & 1 \\
\hline Viés & $b$ & $b=\frac{1}{N} \sum_{i=1}^{N}\left(\phi_{i}-\psi_{i}\right)$ & 0 \\
\hline Erro Absoluto Médio & $E A$ & $E A=\frac{1}{N} \sum_{i=1}^{N}\left|\phi_{i}-\psi_{i}\right|$ & 0 \\
\hline Erro Quadrático Médio & $E Q$ & $E Q=\left[\frac{1}{N} \sum_{i=1}^{N}\left(\phi_{i}-\psi_{i}\right)^{2}\right]^{1 / 2}$ & 0 \\
\hline
\end{tabular}


Tabela 2: Instituições/Centros (Países) dos modelos do CMIP5 utilizados no estudo.

\begin{tabular}{|c|c|c|c|}
\hline Instituições/Centros (Países) & Modelo & Lat & Lon \\
\hline \multirow{2}{*}{$\begin{array}{l}\text { CSIRO (Commonwealth Scientific and Industrial Research } \\
\text { Organisation), BOM (Bureau of Meteorology) (Australia) }\end{array}$} & ACCESS1-0 & 145 & 192 \\
\hline & ACCESS1.3 & 145 & 192 \\
\hline \multirow{2}{*}{$\begin{array}{l}\text { BCC (Beijing Climate Center), China Meteorological Administration } \\
\text { (China) }\end{array}$} & bcc-csm1-1-m & 160 & 320 \\
\hline & bcc-csm1-1 & 64 & 128 \\
\hline $\begin{array}{c}\text { GCESS (Global Change and Earth System Science), BNU (Beijing } \\
\text { Normal University) (China) }\end{array}$ & BNU-ESM & 64 & 128 \\
\hline $\begin{array}{l}\text { CCCma (Canadian Centre for Climate Modelling and Analysis) } \\
\text { (Canada) }\end{array}$ & CanESM2 & 64 & 128 \\
\hline NCAR (National Center for Atmospheric Research) (EUA) & CCSM4 & 192 & 288 \\
\hline \multirow{2}{*}{ NSF/DOE NCAR (National Center for Atmospheric Research) (EUA) } & CESM1-BGC & 192 & 288 \\
\hline & CESM1-CAM5 & 192 & 288 \\
\hline \multirow{2}{*}{ CMCC (Centro Euro-Mediterraneo per Cambiamenti) (Itália) } & CMCC-CM & 240 & 480 \\
\hline & CMCC-CMS & 96 & 192 \\
\hline $\begin{array}{c}\text { CNRM (Centre National de Recherches Meteorologiques), } \\
\text { CERFACS (Centre Europeen de Recherches et de Formation } \\
\text { Avanceeen Calcul Scientifique) (França) }\end{array}$ & CNRM-CM5 & 128 & 256 \\
\hline $\begin{array}{l}\text { CSIRO, Marine and Atmospheric Research (Melbourne), QCCCE } \\
\text { (Queensland Climate Change Centre of Excellence) (Australia) }\end{array}$ & CSIRO-Mk3-6-0 & 96 & 192 \\
\hline $\begin{array}{l}\text { IAP (Institute of Atmospheric Physics, Chinese Academy of } \\
\text { Sciences), THU (Tsinghua University) (China) }\end{array}$ & FGOALS_g2 & 60 & 128 \\
\hline IAP,CAS(Chinese Academy of Sciences) (China) & FGOALS-s2 & 108 & 128 \\
\hline FIO (The First Institution of Oceanography) (China) & FIO-ESM & 64 & 128 \\
\hline \multirow{3}{*}{$\begin{array}{l}\text { NOAA/GFDL (National Oceanic and Atmospheric Administration/ } \\
\text { Geophysical Fluid Dynamics Laboratory) (EUA) }\end{array}$} & GFDL-CM3 & 90 & 144 \\
\hline & GFDL-ESM2G & 90 & 144 \\
\hline & GFDL-ESM2M & 90 & 144 \\
\hline \multirow{4}{*}{ NASA/GISS (Goddard Institute for Space Studies) (EUA) } & GISS-E2-H-CC & 90 & 144 \\
\hline & GISS-E2-H & 90 & 144 \\
\hline & GISS-E2-R-CC & 90 & 144 \\
\hline & GISS-E2-R & 90 & 144 \\
\hline NIMR (National Institute of Meteorological Research) (Coréia do Sul) & HadGEM2-AO & 145 & 192 \\
\hline \multirow{2}{*}{ Met Office Hadley Centre (Reino Unido) } & HadGEM2-CC & 145 & 192 \\
\hline & HadGEM2-ES & 145 & 192 \\
\hline INM (Institute for Numerical Mathematics) (Russia) & inmcm4 & 120 & 180 \\
\hline \multirow{3}{*}{ IPSL (Institut Pierre Simon Laplace) (França) } & IPSL-CM5A-LR & 96 & 96 \\
\hline & IPSL-CM5A-MR & 143 & 144 \\
\hline & IPSL-CM5B-LR & 96 & 96 \\
\hline \multirow{3}{*}{$\begin{array}{c}\text { AORI (Atmosphere and Ocean Research Institute), NIES (National } \\
\text { Institute for Environmental Studies), JAMSTEC (Japan Agency for } \\
\text { Marine-Earth Science and Technology) (Japão) }\end{array}$} & MIROC5 & 128 & 256 \\
\hline & MIROC-ESM-CHEM & 64 & 128 \\
\hline & MIROC-ESM & 64 & 128 \\
\hline \multirow{2}{*}{ MPIM (Max Planck Institute for Meteorology) (Alemanha) } & MPI-ESM-LR & 96 & 192 \\
\hline & MPI-ESM-MR & 96 & 192 \\
\hline MRI (Meteorological Research Institute) (Japão) & MRI-CGCM3 & 160 & 320 \\
\hline \multirow{2}{*}{ Norwegian Climate Centre (Noruega) } & NorESM1-ME & 96 & 144 \\
\hline & NorESM1-M & 96 & 144 \\
\hline
\end{tabular}


e sul do NEB (NNEB e SNEB, respectivamente). As Tabelas 3 e 4 (Tabelas 5 e 6 ) apresentam os índices estatísticos calculados para o ciclo anual e para as quatro estações austrais sobre as sub-regiões NNEB e SNEB, respectivamente, para a variável precipitação (temperatura).

Quanto aos erros de viés, na porção norte do NEB (Tabelas 3 e 5), nota-se que, na média anual, em relação ao CRU, o RAMS é mais úmido e menos frio $(1,415 \mathrm{~mm} / \mathrm{dia}$ e $\left.-1,016^{\circ} \mathrm{C}\right)$ comparado ao HadGEM2-ES $(0,429 \mathrm{~mm} / \mathrm{dia}$ e $-1,142^{\circ} \mathrm{C}$ ). Já na porção sul (Tabelas 4 e 6 ), em relação ao banco de dado observado, o modelo regional mantém o viés menos frio $\left(-1,398^{\circ} \mathrm{C}\right)$ comparado ao modelo global $\left(-1,613^{\circ} \mathrm{C}\right)$, porém possui um viés ligeiramente seco $(-0,162 \mathrm{~mm} / \mathrm{dia})$ comparado ao ligeiramente úmido do HadGEM2-ES $(0,130 \mathrm{~mm} / \mathrm{dia})$.

Para os erros absolutos e quadrático médio, na média anual da precipitação, o RAMS6.0 simula maiores (menores) erros no setor norte (sul) do NEB comparado ao HadGEM2-ES, segundo a Tabela 3 (Tabela 4). Já para a temperatura, em ambas as regiões, o modelo regional apresenta menores valores comparados ao global (Tabelas 5 e 6 ).

Para a precipitação climatológica mensal, o RAMS6.0 possui uma correlação com as observações do CRU próximo à do HadGEM2-ES, porém ligeiramente menor, tanto sobre o NNEB $(0,961$ e 0,966 , respectivamente - Tabela 3$)$, quanto sobre o SNEB $(0,897$ e 0,913 , respectivamente - Tabela 4). Esses valores de correlação satisfazem o teste de significância estatística proposto neste trabalho.

Sobre o setor norte do NEB (Tabela 3), ambos os modelos sobrestimam a precipitação de verão (DJF) e outono (MAM) austral (em maior grau pelo modelo regional, o qual sobrestima também o mês de junho) e subestimam a de inverno (JJA) e primavera (SON) austral (em maior grau pelo HadGEM2-ES - Tabela 3). Semelhante ao erro de viés, o RAMS6.0 possui maiores (menores) erros absoluto e quadrático médio em DJF e MAM (JJA e SON) comparado ao HadGEM2-ES. Quanto ao pico de máxima precipitação observada em março (CRU),

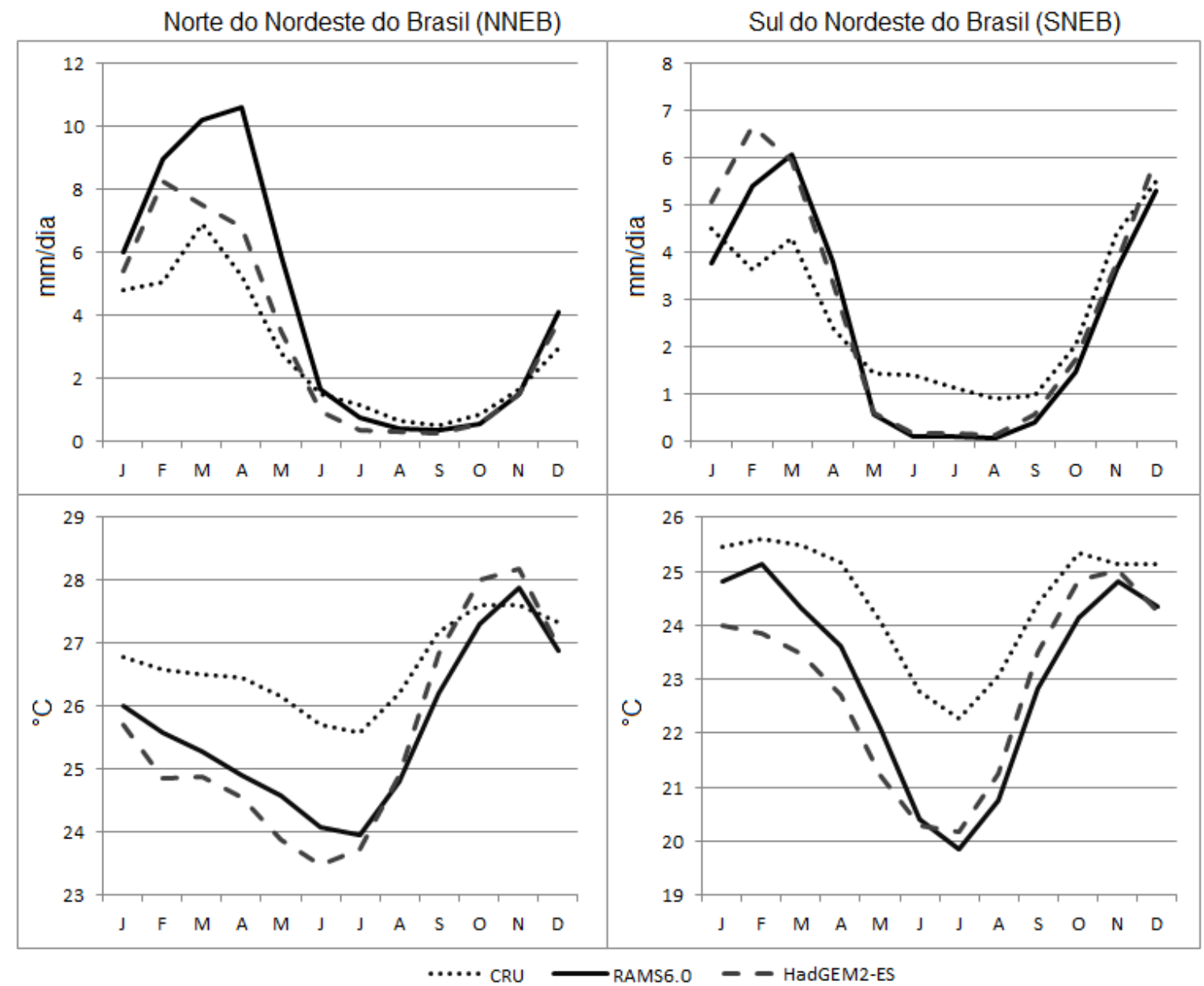

Figura 2 - Climatologia da precipitação (painéis de cima) e temperatura (painéis de baixo) apresentada pelo RAMS (linha sólida - modelo regional), HadGEM2-ES (linha tracejada - modelo global) e CRU (pontilhado - dado observado), no Norte (esquerda) e Sul (direita) do Nordeste brasileiro, de 1986 a 2005. 
Tabela 3 - Índices estatísticos calculados pelos modelos RAMS6.0 e HadGEM2-ES, em relação ao CRU, para a precipitação acumulada média anual e sazonal, na sub-região norte do NEB (NNEB). Os valores com cores em cinza são os que estão mais próximos do valor ideal de cada índice.

\begin{tabular}{ccccccc}
\hline Índice Estatístico & Modelos & Ciclo Anual & DJF & MAM & JJA & SON \\
\hline \multirow{2}{*}{ Correlação } & RAMS6.0 & 0,961 & - & - & - & - \\
& HadGEM2-ES & 0,966 & - & - & - & - \\
\hline \multirow{2}{*}{ Viés } & RAMS6.0 & 1,415 & 2,102 & 3,917 & $-0,163$ & $-0,195$ \\
& HadGEM2-ES & 0,429 & 1,566 & 0,963 & $-0,558$ & $-0,256$ \\
\hline \multirow{2}{*}{ Erro Absoluto Médio } & RAMS6.0 & 1,619 & 2,102 & 3,917 & 0,263 & 0,195 \\
& HadGEM2-ES & 0,836 & 1,566 & 0,963 & 0,558 & 0,256 \\
\hline \multirow{2}{*}{ Erro Quadrático Médio } & RAMS6.0 & 2,375 & 2,456 & 4,051 & 0,280 & 0,211 \\
& HadGEM2-ES & 1,156 & 1,955 & 1,055 & 0,584 & 0,265 \\
\hline
\end{tabular}

Tabela 4 - Índices estatísticos calculados pelos modelos RAMS6.0 e HadGEM2-ES, em relação ao CRU, para a precipitação acumulada média anual e sazonal, na sub-região sul do NEB (SNEB). Os valores com cores em cinza são os que estão mais próximos do valor ideal de cada índice.

\begin{tabular}{ccccccc}
\hline Índice Estatístico & Modelos & Ciclo Anual & DJF & MAM & JJA & SON \\
\hline \multirow{2}{*}{ Correlação } & RAMS6.0 & 0,897 & - & - & - & - \\
& HadGEM2-ES & 0,913 & - & - & - & - \\
\hline \multirow{2}{*}{ Viés } & RAMS6.0 & $-0,162$ & 0,287 & 0,763 & $-1,060$ & $-0,639$ \\
& HadGEM2-ES & 0,130 & 1,367 & 0,586 & $-0,983$ & $-0,451$ \\
\hline \multirow{2}{*}{ Erro Absoluto Médio } & RAMS6.0 & 0,986 & 0,905 & 1,340 & 1,060 & 0,639 \\
& HadGEM2-ES & 0,987 & 1,367 & 1,148 & 0,983 & 0,451 \\
\hline \multirow{2}{*}{ Erro Quadrático Médio } & RAMS6.0 & 1,091 & 1,121 & 1,388 & 1,078 & 0,646 \\
& HadGEM2-ES & 1,218 & 1,809 & 1,195 & 1,004 & 0,473 \\
\hline
\end{tabular}

Tabela 5 - Índices estatísticos calculados pelos modelos RAMS6.0 e HadGEM2-ES, em relação ao CRU, para a temperatura média anual e sazonal, na sub-região do norte do NEB (NNEB). Os valores com cores em cinza são os que estão mais próximos do valor ideal de cada índice.

\begin{tabular}{ccccccc}
\hline Índice Estatístico & Modelos & Anual & DJF & MAM & JJA & SON \\
\hline \multirow{2}{*}{ Correlação } & RAMS6.0 & 0,979 & - & - & - & - \\
& HadGEM2-ES & 0,967 & - & - & - & - \\
\hline \multirow{2}{*}{ Viés } & RAMS6.0 & $-1,016$ & $-0,730$ & $-1,453$ & $-1,547$ & $-0,333$ \\
& HadGEM2-ES & $-1,142$ & $-1,063$ & $-1,930$ & $-1,783$ & 0,210 \\
\hline \multirow{2}{*}{ Erro Absoluto Médio } & RAMS6.0 & 1,064 & 0,730 & 1,453 & 1,547 & 0,527 \\
& HadGEM2-ES & 1,305 & 1,063 & 1,930 & 1,783 & 0,443 \\
\hline \multirow{2}{*}{ Erro Quadrático Médio } & RAMS6.0 & 1,173 & 0,766 & 1,461 & 1,550 & 0,617 \\
& HadGEM2-ES & 1,480 & 1,198 & 1,948 & 1,824 & 0,454 \\
\hline
\end{tabular}

Tabela 6 - Índices estatísticos calculados pelos modelos RAMS6.0 e HadGEM2-ES, em relação ao CRU, para a temperatura média anual e sazonal, na sub-região do sul do NEB (SNEB). Os valores com cores em cinza são os que estão mais próximos do valor ideal de cada índice.

\begin{tabular}{ccccccc}
\hline Índice Estatístico & Modelos & Anual & DJF & MAM & JJA & SON \\
\hline \multirow{2}{*}{ Correlação } & RAMS6.0 & 0,982 & - & - & - & - \\
& HadGEM2-ES & 0,894 & - & - & - & - \\
\hline \multirow{2}{*}{ Viés } & RAMS6.0 & $-1,398$ & $-0,630$ & $-1,560$ & $-2,377$ & $-1,023$ \\
& HadGEM2-ES & $-1,613$ & $-1,360$ & $-2,443$ & $-2,143$ & $-0,503$ \\
\hline \multirow{2}{*}{ Erro Absoluto Médio } & RAMS6.0 & 1,398 & 0,630 & 1,560 & 2,377 & 1,023 \\
& HadGEM2-ES & 1,613 & 1,360 & 2,443 & 2,143 & 0,503 \\
\hline \multirow{2}{*}{ Erro Quadrático Médio } & RAMS6.0 & 1,576 & 0,644 & 1,593 & 2,377 & 1,151 \\
& HadGEM2-ES & 1,810 & 1,407 & 2,467 & 2,162 & 0,600 \\
\hline
\end{tabular}


o RAMS6.0 atrasa em um (1) mês (simulando em abril), enquanto que o HadGEM2-ES adianta o mesmo em um (1) mês (fevereiro). Quanto ao mês de precipitação mínima, ambos os modelos simulam corretamente em setembro.

Sobre o setor sul do NEB (Tabela 4), os modelos sobrestimam a precipitação que ocorre no verão e no outono austral (porém o RAMS6.0 subestima os meses de dezembro, janeiro e maio, enquanto o HadGEM2-ES o faz apenas em maio) e subestimam a de inverno e primavera. Quanto aos erros absoluto e quadrático médio, o modelo regional apresenta menores valores, comparado ao global, apenas em DJF, porém com valores muito próximos dos apresentados pelo HadGEM2-ES nas outras três estações. Vale ressaltar que o baixo valor de viés do RAMS6.0 em DJF (0,287 mm/dia) comparado ao do HadGEM2-ES (1,367 mm/dia) se dá pela compensação de erros entre a subestimação da precipitação nos meses de dezembro e janeiro e a sobrestimação no mês de fevereiro, ficando evidente no erro absoluto médio $(0,905$ $\mathrm{mm} /$ dia). Sobre a região $\mathrm{SNEB}$ está evidente que há uma compensação de erros por parte dos modelos, em relação ao CRU. Durante as duas estações de maior (menor) precipitação, os modelos apresentam viés chuvoso (seco). Isso reflete, na média anual, em um erro de viés próximo de zero.

Apesar de apresentarem vieses reduzidos no mês de precipitação máxima observada (dezembro), ambos os modelos simulam erroneamente este pico (RAMS6.0 em março e HadGEM2-ES em fevereiro). Quanto ao mês de mínima precipitação (em agosto segundo o CRU), os dois modelos atrasam em um (1) mês (setembro).

Já para a temperatura, na média anual, o RAMS6.0 apresentou uma ligeira melhora na correlação com o dado observado ao ser comparado com o do HadGEM2-ES, nas subregiões NNEB $(0,979$ contra 0,967 , respectivamente - Tabela $5)$ e $\operatorname{SNEB}(0,982$ contra 0,894 , respectivamente - Tabela 6).
Ambos os modelos apresentaram valores de correlação que passam no teste de significância adotado.

Para o NNEB (Tabela 5), RAMS6.0 subestima a temperatura em todas as estações, enquanto o HadGEM2-ES sobrestima apenas na primavera austral. Quanto aos erros absoluto e quadrático médio, o modelo global apresenta valores mais próximos do ideal apenas na primavera austral. Para o mês de temperatura média máxima, que ocorre em outubro segundo o dado do CRU, os modelos atrasam em um (1) mês (novembro). Já para o mês de temperatura média mínima, o modelo regional simula corretamente em julho, enquanto o global antecipa em um (1) mês, simulando em junho.

Para o setor sul (SNEB), ambos os modelos subestimaram a temperatura média durante todo o ano. Os maiores erros de viés acontecem no outono e inverno austral. RAMS6.0 apresenta menores erros de viés, absoluto e quadrático médio, comparado ao HadGEM2-ES, no verão e outono austral. O modelo regional simula corretamente os meses de temperatura média máxima e mínima anual observada, em fevereiro e julho, respectivamente, enquanto o modelo global simula corretamente apenas o mês de temperatura média mínima anual, representando a temperatura média máxima anual em novembro.

A Figura 3 apresenta a média anual dos campos de precipitação no período analisado. O CRU mostra que o mínimo de precipitação ocorre no sertão central, porém o HadGEM2-ES simula este mínimo na costa leste nordestina, e o RAMS6.0 reforça tal erro. O máximo apresentado nessa região, no estado do Maranhão, é simulado mais a leste pelos modelos, com maior intensidade pelo RAMS6.0, atingindo até o Piauí. O campo de precipitação médio anual do CRU está qualitativamente de acordo com os mapas médios anual apresentados por outros conjuntos de dados apresentados por Pinto et al. (2009). Os autores compararam a precipitação para a América do Sul a partir de cinco bancos de dados: TRMM, CMAP, GPCP,

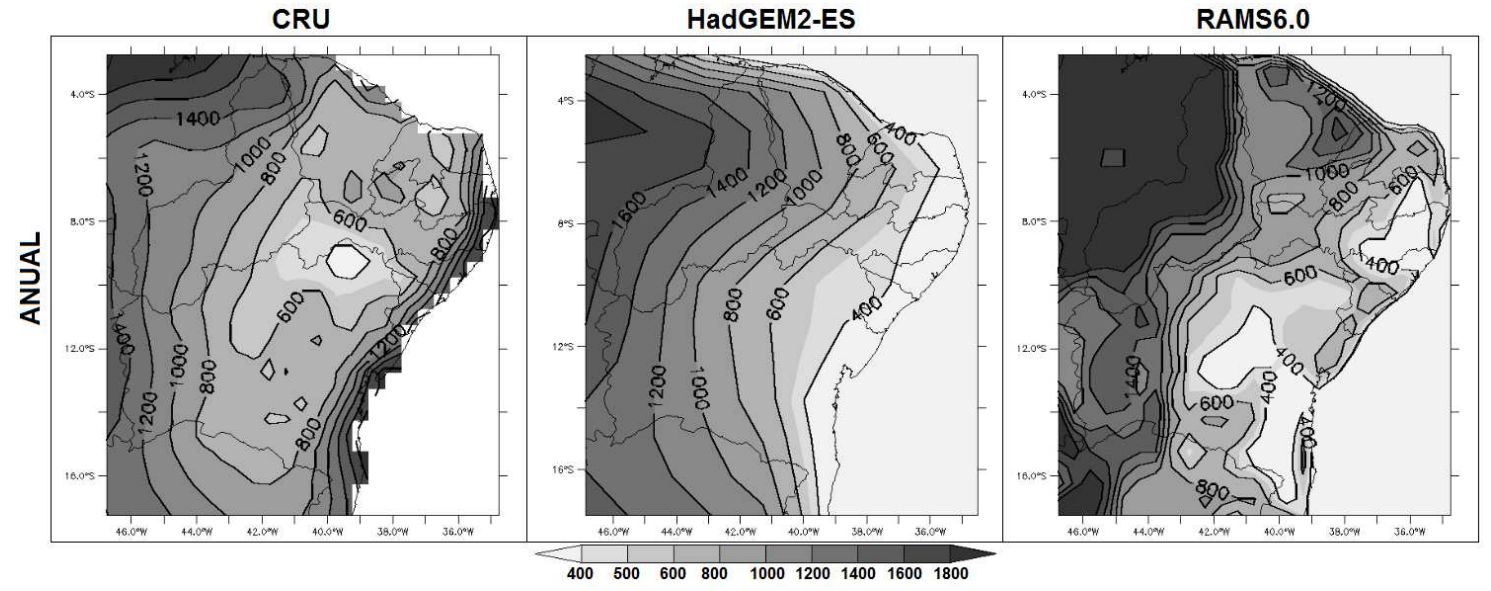

Figura 3 - Mapas dos campos da precipitação acumulada média anual para os dados do CRU (primeira coluna), e simulações do HadGEM2-ES (segunda coluna) e RAMS (terceira coluna). Os valores estão em milímetros (mm). 
NCEP/NCAR e CPTEC (os três primeiros são bancos de dados produzidos a partir de sensoriamento remoto e os dois últimos são dados de reanálise), para o período de 2000 a 2004.

A Figura 4 apresenta a média anual de temperatura. Qualitativamente, o modelo regional apresentou um campo mais semelhante ao observado do que o global, porém com um viés frio (de módulo de cerca de $1^{\circ} \mathrm{C}$ ). Pode-se notar o máximo de temperatura na região do Piaú e na divisa do estado do Ceará com Rio Grande do Norte (simulado pelo HadGEM2-ES também), enquanto que o modelo global apresenta máximos apenas na faixa norte do NEB. É notável também o mínimo captado pelo RAMS na parte leste do NEB, e o semelhante padrão no sul do NEB comparado aos dados do CRU (Figura 4).

Os campos médios sazonais de precipitação (CRU) apresentam sua variabilidade temporal e espacial, em que no verão (Figura 5, primeira linha-DJF) é observado acumulados abaixo de $200 \mathrm{~mm}$ em grande parte do leste do NEB, enquanto que o modelo global mantém esse mínimo apenas na costa nordestina, o regional corrige tal erro e reduz a precipitação na região mais dentro do continente. Entretanto, na faixa oeste do NEB, acumulados acima de $600 \mathrm{~mm}$ são erroneamente reproduzidos pelo modelo global (em sua intensidade), este sinal ainda é reforçado pelo regional, com valores de precipitação ultrapassando $1000 \mathrm{~mm}$, bem acima do observado. No outono (Figura 5, segunda linha-MAM), novamente o HadGEM2-ES desloca erroneamente a região de mínima precipitação (abaixo de $200 \mathrm{~mm}$ ) para o leste do NEB e o RAMS corrige parcialmente simulando mais adentro do continente. Nota-se que o modelo regional novamente superestima a precipitação em certas áreas, chegando a valores de 1000 mm no Maranhão e Piauí.

O modelo regional, devido à sua maior resolução, consegue detalhar e capturar os acumulados na costa leste. No entanto, de uma forma geral, ambos os modelos capturam os padrões espaciais na porção norte do NEB, contudo apresentam erro sistemático sobre os estados do Maranhão e Piauí, destacando valores bastante superestimados pelo RAMS6.0. Esta característica pode ser atribuída a erros sistemáticos da parametrização de convecção do modelo regional (KainFritcsh), baseada na convergência do fluxo de umidade, a qual tende a "secar" o vapor da atmosfera e produzir chuva em excesso.

No inverno austral (Figura 5, terceira linha - JJA), os modelos simulam uma área maior do que o observado da precipitação abaixo de $10 \mathrm{~mm}$, não capturando a precipitação na costa leste nordestina (acima de $400 \mathrm{~mm}$ ) e um pico localizado na Bahia. O modelo regional novamente superestima a precipitação no norte do Maranhão. Finalmente, na primavera (Figura 5, quarta linha-SON), percebe-se que os modelos apresentaram o mínimo na costa norte do NEB e o máximo de precipitação mais ao sul. Qualitativamente, os modelos tiveram um desempenho satisfatório em simular o padrão de precipitação.

Na Figura 2 do trabalho de Sales e Xue (2011), são apresentadas as precipitações médias sazonais de verão (DJF de 1988-89 e DJF de 1997-98) e inverno (JJA de 1988 e JJA de 1997) austrais sobre a América do Sul para o banco de dado observado do CPC, e simulados pelo GCM NCEP T62 e o RCM ETA. Ao comparar os campos apresentados entre este trabalho e o de Sales e Xue (2011), nota-se que os campos sazonais médios apresentados pelos conjuntos de dados observados (CRU e CPC) e os simulados pelos modelos globais (HadGEM2-ES e NCEP T62) e regionais (RAMS6.0 e ETA) são, qualitativamente, semelhantes.

O banco de dado do CRU apresenta uma precipitação mais elevada no litoral norte do NEB no inverno comparado ao CPC, porém, neste último foram estudados apenas dois períodos pontuais. Percebe-se também que os modelos regionais simularam uma precipitação elevada, no verão, próxima a região do Piauí e do Maranhão, algo que não é encontrado nos campos observados.

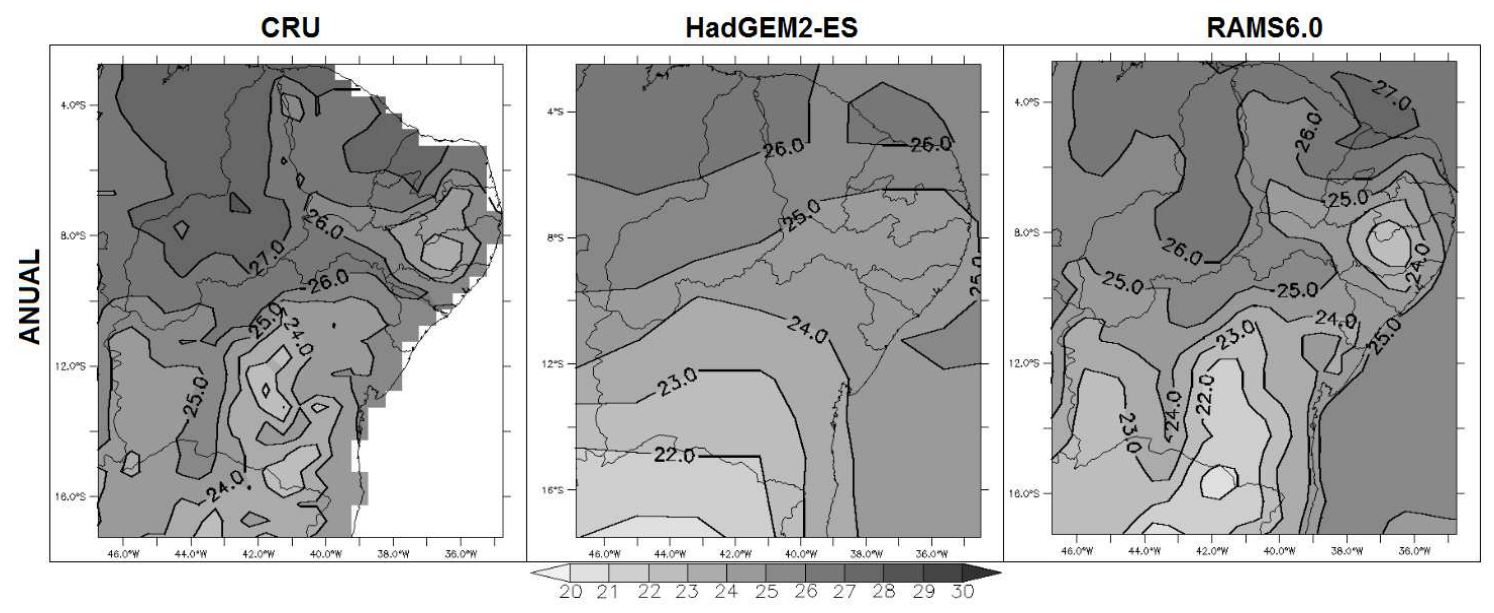

Figura 4 - Mapas dos campos da temperatura anual para os dados do CRU (primeira coluna), simulações do HadGEM2-ES (segunda coluna) e RAMS (terceira coluna). Os valores estão em Celsius $\left({ }^{\circ} \mathrm{C}\right)$. 


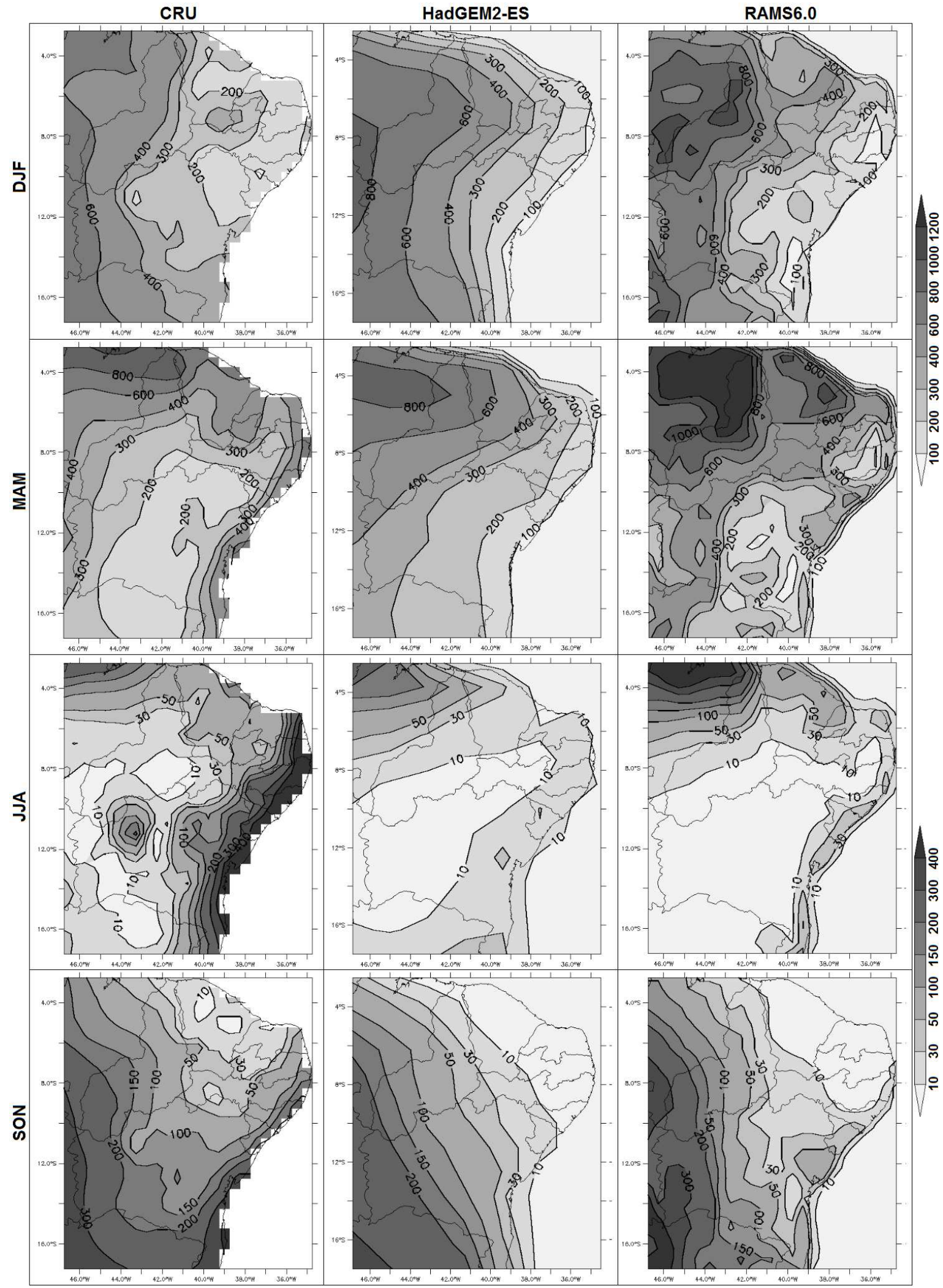

Figura 5 - Mapas dos campos da precipitação acumulada das estações de verão (primeira linha), outono (segunda linha), inverno (terceira linha) e primavera (quarta linha) austral, para os dados do CRU (primeira coluna), simulações do HadGEM2-ES (segunda coluna) e RAMS (terceira coluna). Os valores estão em milímetros ( $\mathrm{mm})$. 
Para os campos médios sazonais de temperatura, no verão (Figura 6, primeira linha - DJF), o HadGEM2-ES apresenta o máximo na região norte do NEB (com erros de viés da ordem de -1 grau), enquanto o RAMS6.0 apresenta um padrão mais semelhante ao CRU, identificando valores mínimos no leste do NEB, e valores máximos nas divisas de Piauí e Maranhão, e Ceará e Rio Grande do Norte (porém com viés frio). No outono (Figura 6, segunda linha - MAM), o viés frio do modelo regional aumenta (em comparação ao trimestre anterior), porém mantendo um campo de temperatura com padrões semelhantes ao observado, enquanto o global apresenta uma redução da temperatura no interior do continente. No inverno (Figura 6, terceira linha - JJA), o viés frio do modelo regional atinge o máximo, onde tanto o $\mathrm{MCG}$, quanto o $\mathrm{MCR}$, apresentam uma região leste mais fria que a região oeste (porém com mais detalhamento por parte do RAMS6.0). Finalmente, na primavera (Figura 6, quarta linha - SON), o modelo global subestimou a extensão da região de máxima temperatura no Maranhão e no Piauí, e não identificou o mínimo na Paraíba, diferentemente do regional, que apresentou tais padrões, porém com viés frio.

Tanto para os mapas dos campos da precipitação e temperatura anual média (Figuras 3 e 4, respectivamente), e sazonal média (Figuras 5 e 6, respectivamente), nota-se uma melhor da distribuição espacial do RAMS em relação ao modelo HadGEM2-ES, devido à melhor representação da topografia por parte do modelo regional.

\subsection{Projeções para o clima futuro}

A Figura 7 apresenta a diferença de climatologia da precipitação e temperatura entre os três períodos futuros e o histórico em ambas as sub-regiões. As Tabelas 7 e 8 (Tabelas 9 e 10) trazem o valor dessa diferença da média espacial, para a precipitação, em porcentagem (temperatura, em graus Celsius), respectivamente, para as sub-regiões NNEB e SNEB, tanto anualmente, quanto sazonalmente.

Analisando a diferença da climatologia entre os períodos futuros e o presente, para a precipitação (Figura 7, painel de cima, e Tabelas 7 e 8), nota-se que as maiores mudanças ocorreram nos meses dentro da estação chuvosa, para ambas as sub-regiões. No verão austral (DJF), os dois modelos projetam aumento da precipitação (exceto o HadGEM2-ES em médio prazo no NNEB) e em maior grau em longo prazo simulado pelo RAMS6.0.

Já no outono austral (MAM), a mudança percentual em módulo é inferior à estação anterior (exceto para o HadGEM2-ES em médio prazo no NNEB). No NNEB, RAMS6.0 simula aumento para as três fatias de tempo, enquanto o HadGEM2-ES o faz apenas em curto prazo, projetando redução desta variável para as últimas "fatias de tempo". No SNEB, os dois modelos projetam de forma semelhante, redução em curto prazo e aumento em médio e longo prazo. Ressalta-se que o HadGEM2-ES possui características contrárias nas porções norte e sul do NEB.

Para o inverno austral (JJA), nos dois setores do NEB, o padrão de projeção de ambos os modelos são semelhantes, aumento da precipitação em curto prazo (em maior grau pelo RAMS6.0) e redução em médio e longo prazo (exceto o HadGEM2-ES, que sobre o SNEB, simula em médio prazo um aumento de 2,64\% da precipitação). Por último, na primavera austral (SON), os modelos projetam redução da precipitação (exceto o RAMS6.0 em curto prazo no NNEB) em ambas as sub-regiões, com valores mais expressivos no final do século.

Para a média anual, RAMS6.0 simula apenas aumento da precipitação média no NEB, em maior grau em curto prazo no NNEB (17,58\%) e em longo prazo $(25,28 \%$ e $19,52 \%$, para o NNEB e SNEB, respectivamente). Já o HadGEM2-ES projeta mudanças anuais em menor grau comparado ao RAMS6.0. Para o setor norte do NEB, o cenário obtido é de aumento em curto prazo $(6,5 \%)$ e redução em médio $(-9,15 \%)$ e longo $(-5,06 \%)$ prazo. No setor sul, a perspectiva apontada pelo modelo é de redução em curto $(-0,05 \%)$ e médio $(-2,45 \%)$ prazo e aumento a longo $(3,94 \%)$ prazo.

As projeções de temperatura (Figura 7, painel inferior, e Tabelas 9 e 10) do modelo global e o regional mostram aumento ao longo do século em ambas as sub-regiões. Os aumentos indicados são da ordem de $1,0^{\circ} \mathrm{C}$ (curto prazo), $2,8^{\circ} \mathrm{C}$ (médio prazo) e $5,0^{\circ} \mathrm{C}$ (longo prazo) - Tabelas 9 e 10 . A diferença entre os modelos estão nas mudanças sazonais. Enquanto o HadGEM2-ES apresenta pequenas variações durante o ano $\left(0,55^{\circ} \mathrm{C}\right.$ e $0,49^{\circ} \mathrm{C}$ em curto prazo, $0,51^{\circ} \mathrm{C}$ e $0,47^{\circ} \mathrm{C}$ em médio prazo e $0,99^{\circ} \mathrm{C}$ e $1,12^{\circ} \mathrm{C}$ em longo prazo, para o NNEB e SNEB respectivamente), o RAMS6.0 apresenta variações maiores em médio e longo prazo $\left(2,00^{\circ} \mathrm{C}\right.$ e $2,43^{\circ} \mathrm{C}$ em curto prazo, e $2,87^{\circ} \mathrm{C}$ e $3,67^{\circ} \mathrm{C}$ em longo prazo, para o NNEB e SNEB respectivamente). Esta diferença pode ser observada na Figura 7 (painéis de baixo) e é um importante tema de discussão, uma vez que ambos apontam mudanças semelhantes na média anual, porém de forma diferente nas médias sazonais.

A Figura 8 apresenta os mapas anuais médios da diferença entre a precipitação futura e presente, simulada pelos modelos, para os três períodos mencionados. Em curto prazo (Figura 8, primeira coluna), o modelo regional projeta redução da precipitação ao sul do NEB (redução de até 50 $\mathrm{mm}$ ) e aumento máximo acima de $400 \mathrm{~mm}$ na região norte do Maranhão, Piauí e Ceará; já o global projeta redução também ao sul do NEB e aumento na porção norte (porém em menor grau comparado ao RAMS6.0). Em médio prazo (Figura 8, segunda coluna), o RAMS6.0 projeta, de uma forma geral, 


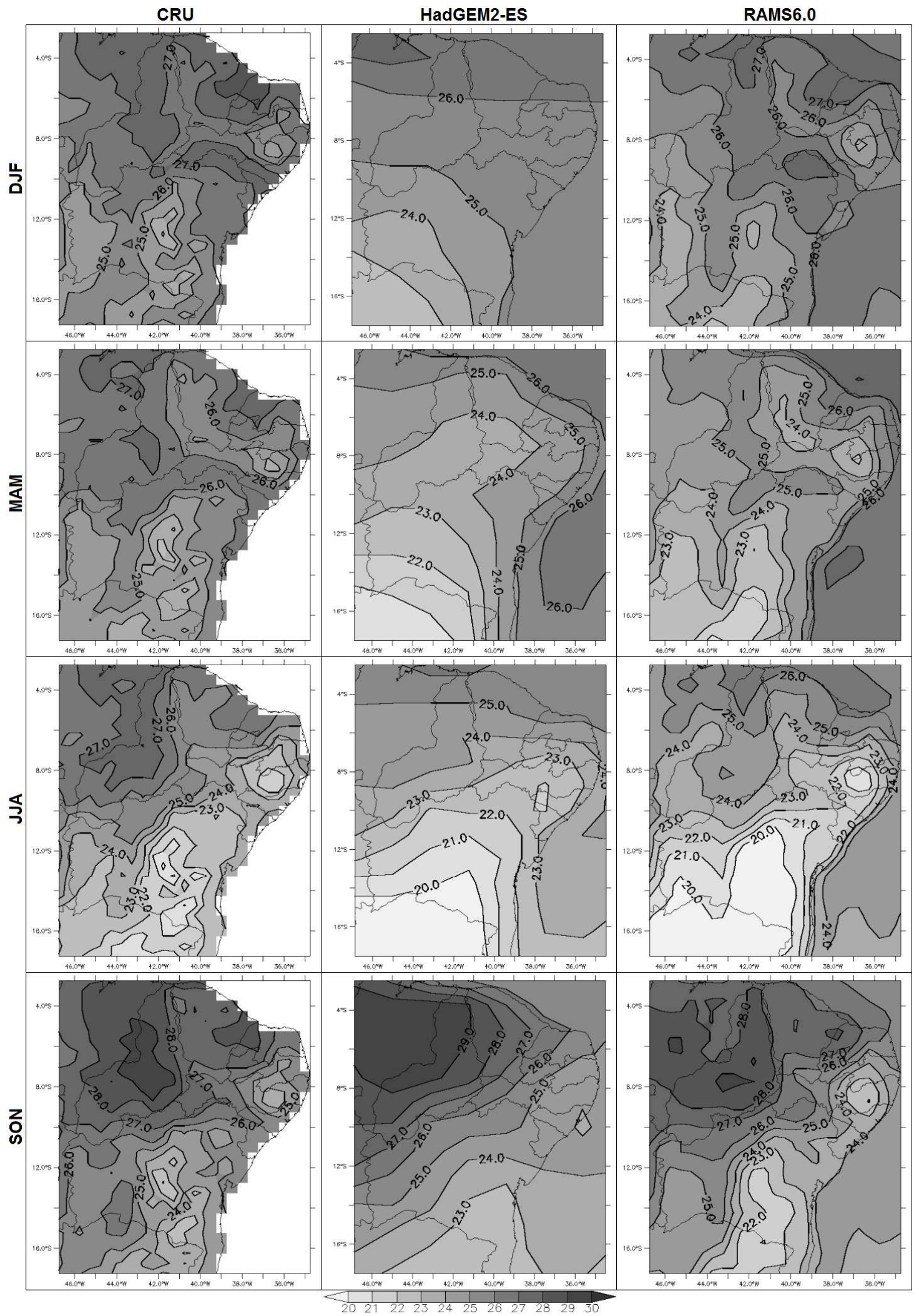

Figura 6: Mapas dos campos da temperatura média das estações de verão (primeira linha), outono (segunda linha), inverno (terceira linha) e primavera (quarta linha) austral, para os dados do CRU (primeira coluna), simulações do HadGEM2-ES (segunda coluna) e RAMS (terceira coluna). Os valores estão em graus Celsius $\left({ }^{\circ} \mathrm{C}\right)$. 


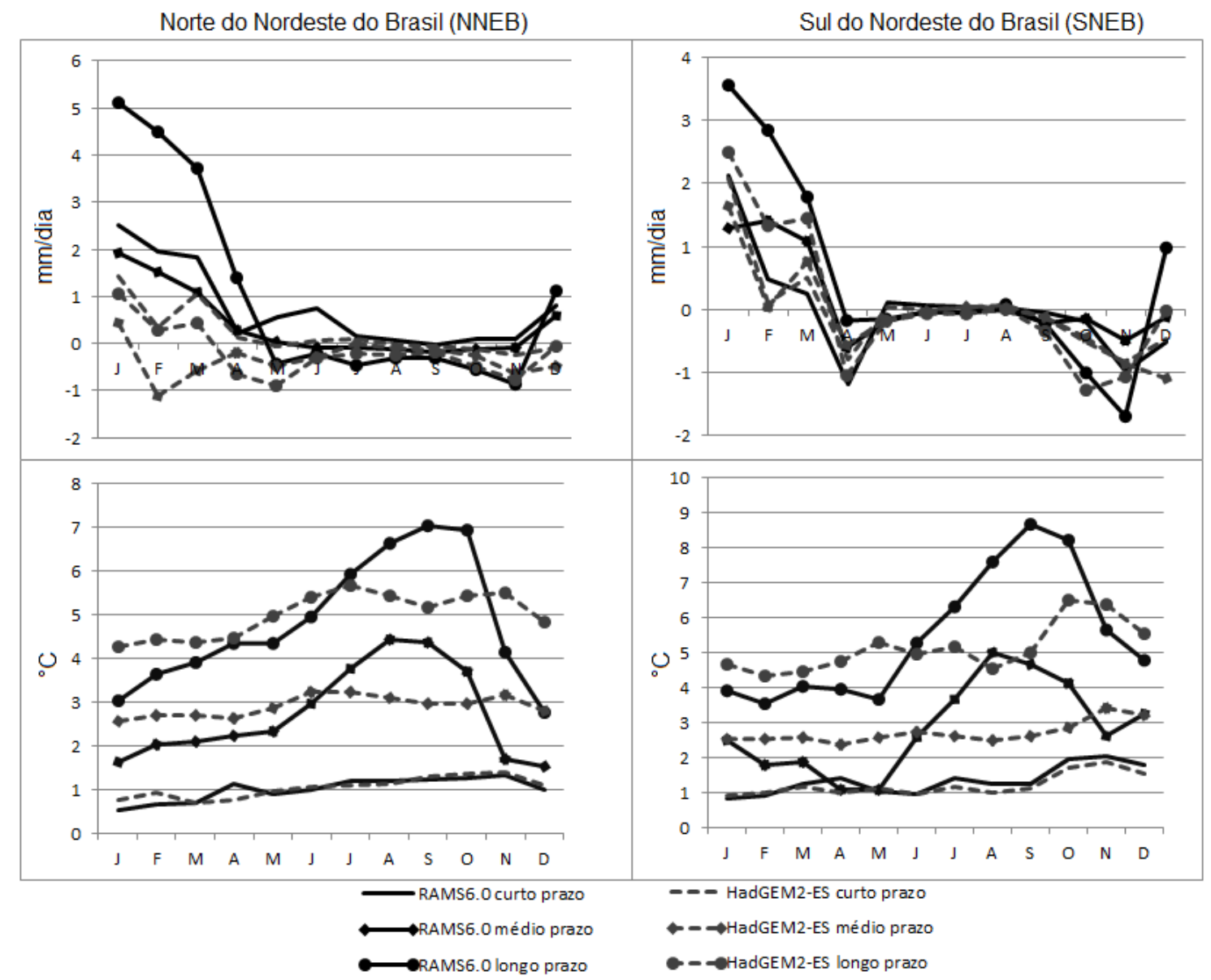

Figura 7 - Diferença das climatologias futuras e presente da precipitação (cima) e temperatura (baixo) simulado pelo RAMS (linha sólida) e HadGEM2-ES (linha tracejada), sobre as sub-regiões NNEB (esquerda) e SNEB (direita).

Tabela 7: Porcentagem da mudança da precipitação média, no norte do NEB (NNEB), comparando os períodos de tempo futuros com o presente, simuladas pelos modelos HadGEM2-ES e RAMS. Os valores em cinza apresentam onde há aumento dessa variável.

\begin{tabular}{ccccccc}
\hline \multirow{2}{*}{ Modelo } & \multirow{2}{*}{ "Fatia de Tempo" } & \multicolumn{5}{c}{ Aumento/redução em \% em comparação com o período histórico } \\
\cline { 2 - 7 } & & DJF & MAM & JJA & SON & Anual \\
\hline \multirow{3}{*}{ RAMS6.0 } & Curto prazo & 27,66 & 9,70 & 33,57 & 6,88 & 17,58 \\
\cline { 2 - 7 } & Médio prazo & 21,58 & 5,54 & $-7,86$ & $-12,96$ & 9,91 \\
\cline { 2 - 7 } & Longo prazo & 56,47 & 17,67 & $-32,86$ & $-67,61$ & 25,28 \\
\hline \multirow{3}{*}{ HadGEM2-ES } & Curto prazo & 9,66 & 6,35 & 9,05 & $-18,28$ & 6,50 \\
\cline { 2 - 7 } & Médio prazo & $-6,13$ & $-6,71$ & $-23,11$ & $-41,45$ & $-9,15$ \\
\cline { 2 - 7 } & Longo prazo & 7,41 & $-6,08$ & $-46,96$ & $-62,75$ & $-5,06$ \\
\hline
\end{tabular}

Tabela 8: Porcentagem da mudança da precipitação média, no sul do NEB (SNEB), comparando os períodos de tempo futuros com o presente, simuladas pelos modelos HadGEM2-ES e RAMS. Os valores em cinza apresentam onde há aumento dessa variável.

\begin{tabular}{ccccccc}
\hline \multirow{2}{*}{ Modelo } & \multirow{2}{*}{ "Fatia de Tempo" } & \multicolumn{5}{c}{ Aumento/redução em \% em comparação com o período histórico } \\
\cline { 3 - 7 } & & DJF & MAM & JJA & SON & Anual \\
\hline \multirow{3}{*}{ RAMS6.0 } & Curto prazo & 14,39 & $-8,20$ & 34,60 & $-22,28$ & 0,29 \\
\cline { 2 - 7 } & Médio prazo & 18,19 & 3,27 & $-14,45$ & $-14,76$ & 6,92 \\
\cline { 2 - 7 } & Longo prazo & 51,27 & 14,31 & $-4,94$ & $-52,80$ & 19,52 \\
\hline \multirow{3}{*}{ HadGEM2-ES } & Curto prazo & 9,50 & $-2,64$ & 17,24 & $-25,04$ & $-0,05$ \\
\cline { 2 - 7 } & Médio prazo & 3,34 & 0,09 & 2,64 & $-23,89$ & $-2,45$ \\
\cline { 2 - 7 } & Longo prazo & 21,64 & 2,59 & $-20,28$ & $-43,48$ & 3,94 \\
\hline
\end{tabular}


Tabela 9 - Diferença entre a temperatura média futura e o presente $\left(\mathrm{em}^{\circ} \mathrm{C}\right)$, no norte do NEB, simulados pelos modelos HadGEM2-ES e RAMS.

\begin{tabular}{ccccccc}
\hline \multirow{2}{*}{ Modelo } & \multirow{2}{*}{ "Fatia de Tempo" } & \multicolumn{5}{c}{ Aumento/redução em ${ }^{\circ} \mathrm{C}$ em comparação com o período histórico } \\
\cline { 3 - 7 } & & DJF & MAM & JJA & SON & Anual \\
\hline \multirow{3}{*}{ RAMS6.0 } & Curto prazo & 0,73 & 0,93 & 1,14 & 1,28 & 1,02 \\
\cline { 2 - 7 } & Médio prazo & 1,76 & 2,25 & 3,76 & 3,28 & 2,76 \\
\cline { 2 - 7 } & Longo prazo & 3,19 & 4,22 & 5,86 & 6,06 & 4,83 \\
\hline \multirow{3}{*}{ HadGEM2-ES } & Curto prazo & 0,94 & 0,82 & 1,10 & 1,37 & 1,06 \\
\cline { 2 - 7 } & Médio prazo & 2,70 & 2,75 & 3,21 & 3,04 & 2,93 \\
\cline { 2 - 7 } & Longo prazo & 4,53 & 4,62 & 5,52 & 5,39 & 5,01 \\
\hline
\end{tabular}

Tabela 10 - Diferença entre a temperatura média futura e o presente $\left(\mathrm{em}^{\circ} \mathrm{C}\right)$, no sul do NEB, simulados pelos modelos HadGEM2-ES e RAMS.

\begin{tabular}{ccccccc}
\hline \multirow{2}{*}{ Modelo } & \multirow{2}{*}{ "Fatia de Tempo" } & \multicolumn{5}{c}{ Aumento/redução em ${ }^{\circ} \mathrm{C}$ em comparação com o período histórico } \\
\cline { 2 - 7 } & & DJF & MAM & JJA & SON & Anual \\
\hline \multirow{3}{*}{ RAMS6.0 } & Curto prazo & 1,18 & 1,24 & 1,22 & 1,75 & 1,35 \\
\cline { 2 - 7 } & Médio prazo & 2,54 & 1,39 & 3,78 & 3,82 & 2,88 \\
\cline { 2 - 7 } & Longo prazo & 4,09 & 3,88 & 6,41 & 7,55 & 5,48 \\
\hline \multirow{3}{*}{ HadGEM2-ES } & Curto prazo & 1,17 & 1,09 & 1,05 & 1,58 & 1,22 \\
\cline { 2 - 7 } & Médio prazo & 2,76 & 2,52 & 2,62 & 2,99 & 2,72 \\
\cline { 2 - 7 } & Longo prazo & 4,87 & 4,86 & 4,90 & 5,98 & 5,15 \\
\hline
\end{tabular}

CURTO PRAZO (SHORT-TERM) MÉDIO PRAZO (MID-TERM) LONGO PRAZO (LONG-TERM)

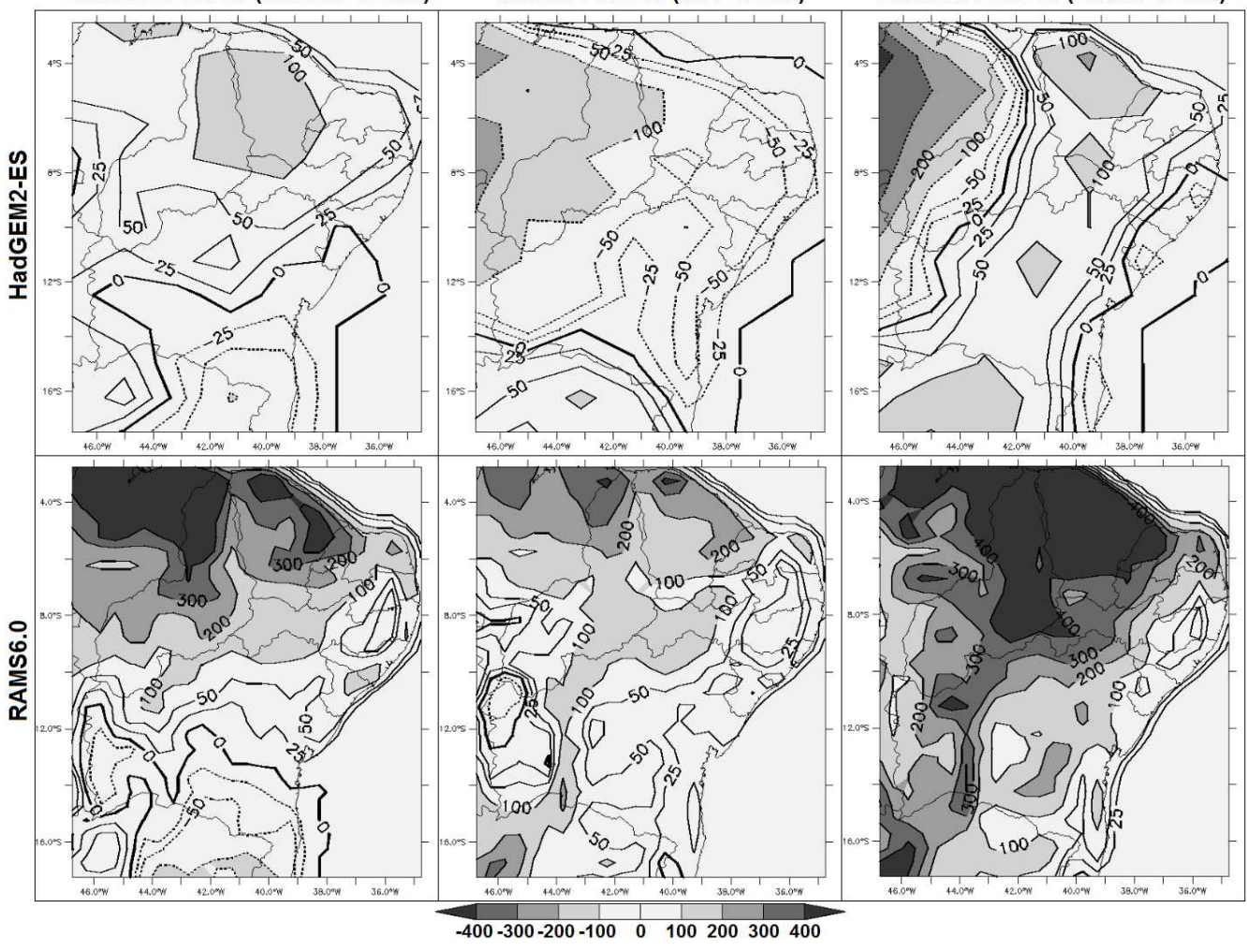

Figura 8 - Mapas da diferença média anual da precipitação acumulada entre os períodos a curto (primeira coluna), médio (segunda coluna) e longo prazo (terceira coluna), e o período presente, simulados pelo HadGEM2-ES (global - primeira linha) e o RAMS6.0 (regional - segunda linha). As linhas tracejadas indicam mudanças negativas e as linhas contínuas indicam mudanças positivas.

aumento da precipitação, principalmente na região norte (chegando a mudanças acima de $200 \mathrm{~mm}$ ) e na parte central do NEB, enquanto o HadGEM2-ES apresenta redução na porção norte do NEB e um ligeiro aumento na porção sul do domínio apresentado. Finalmente, as projeções de longo prazo apresentam elevação geral da precipitação por parte do modelo regional, atingindo variações de $400 \mathrm{~mm}$ no norte do NEB e entre 100 e $300 \mathrm{~mm}$ na região central, enquanto o 
global mantém (como em curto prazo) o padrão de pequena redução no oeste do Maranhão e aumentos acima de $100 \mathrm{~mm}$ em porções do norte do NEB.

A Figura 9 mostra as mudanças no campo de temperatura ao decorrer do século. Os campos produzidos pelo modelo regional são semelhantes ao do modelo global. Em curto prazo, parte do setor norte sofre menores alterações, e a mudança continente adentro fica entre $1^{\circ} \mathrm{C}$ e $2^{\circ} \mathrm{C}$. Já em médio prazo nota-se um aquecimento, principalmente na parte continental, chegando a ultrapassar valores de $3^{\circ} \mathrm{C}$ na porção oeste do NEB. Em longo prazo, o aquecimento ultrapassa os $4^{\circ} \mathrm{C}$ e chega a quase $6^{\circ} \mathrm{C}$ na porção oeste do NEB, com o continente mais aquecido do que o oceano.

\subsubsection{Distribuição $(\Delta \mathbf{P} / \mathbf{P})$ por $\Delta \mathbf{T}$ dos modelos do CMIP5}

A Figura 10 mostra a distribuição da porcentagem da diferença de precipitação pela diferença de temperatura entre as três "fatias de tempo" futuras e o período histórico, sobre as duas sub-regiões estudadas.
Nota-se que o espalhamento dos modelos para a projeção de curto prazo (Figuras 10a e 10b, NNEB e SNEB, respectivamente), para a precipitação, restringe-se entre aumento ou redução de aproximadamente $20 \%$ (exceto para os modelos HadGEM2-CC (número 25) e FGOALS-s2 (número 15), que ultrapassam esse percentual sobre o NNEB e SNEB, respectivamente), porém a média dos modelos encontra-se próxima do valor nulo (com um valor ligeiramente negativo). Sobre o NNEB, o modelo RAMS6.0 simula aumento de 17,58\%, enquanto o HadGEM2-ES (número 26) de 6,50\%. Já sobre o SNEB, ambos os modelos não apresentaram mudanças maiores que $1 \%$. O modelo que projetou maiores reduções para ambas as regiões foi HadGEM2-AO (números 24), de aproximadamente $-20 \%$. Quanto à temperatura, as projeções são de aumento (entre aproximadamente $0,5^{\circ} \mathrm{C}$ e $1,5^{\circ} \mathrm{C}$ ), a média dos modelos (M), o RAMS6.0 e o HadGEM2-ES apresentam um aumento de aproximadamente $1^{\circ} \mathrm{C}$ sobre o NNEB. Os modelos que apresentaram maiores variações positivas de temperatura em curto prazo foram o CanESM2 (número 6, sobre o NNEB) e o MIROC-ESM-CHEM (número 32, sobre o SNEB).

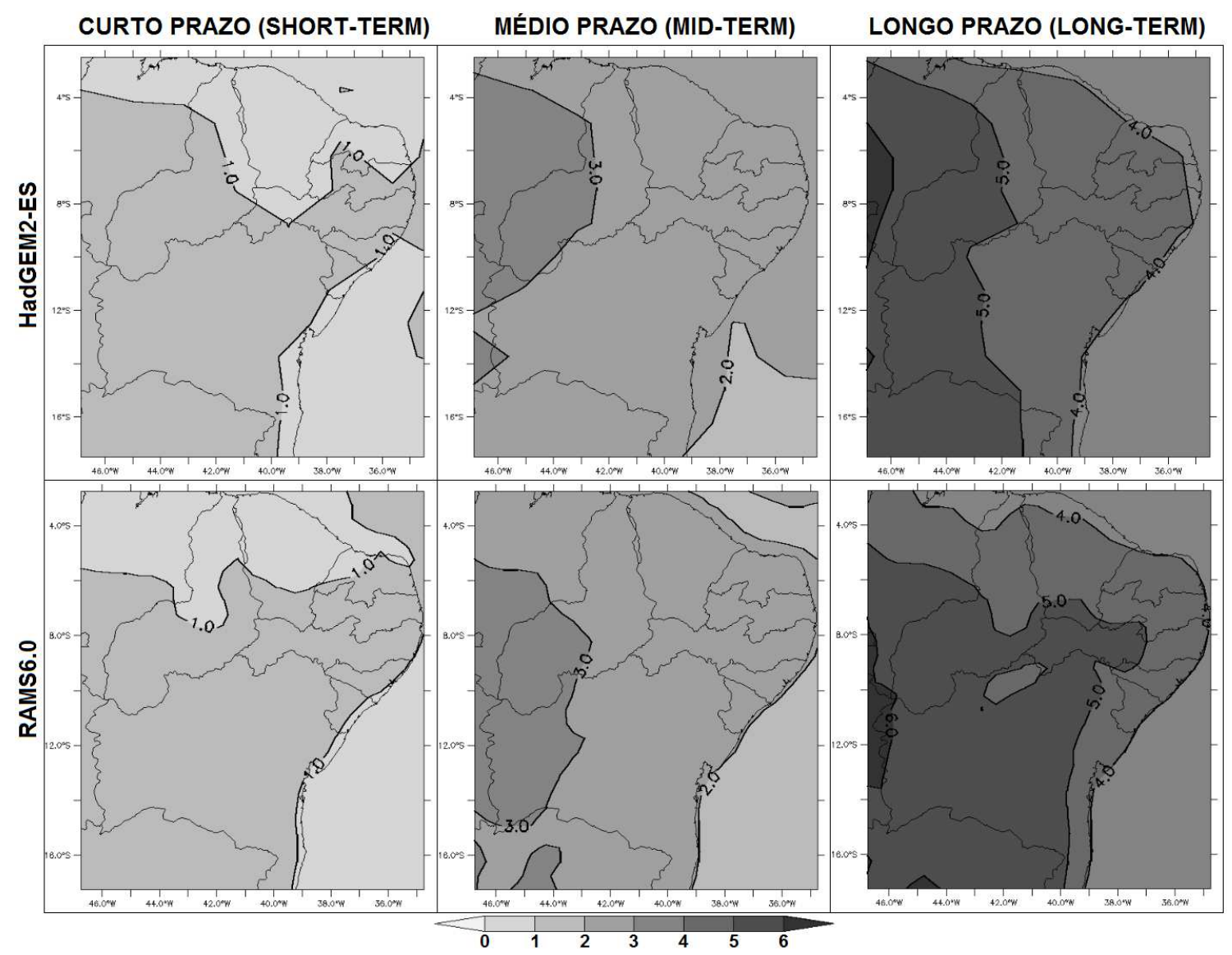

Figura 9 - Mapas da diferença média anual de temperatura entre os períodos a curto (primeira coluna), médio (segunda coluna) e longo prazo (terceira coluna), e o período presente, simulados pelo HadGEM2-ES (global - primeira linha) e RAMS6.0 (regional - segunda linha). 

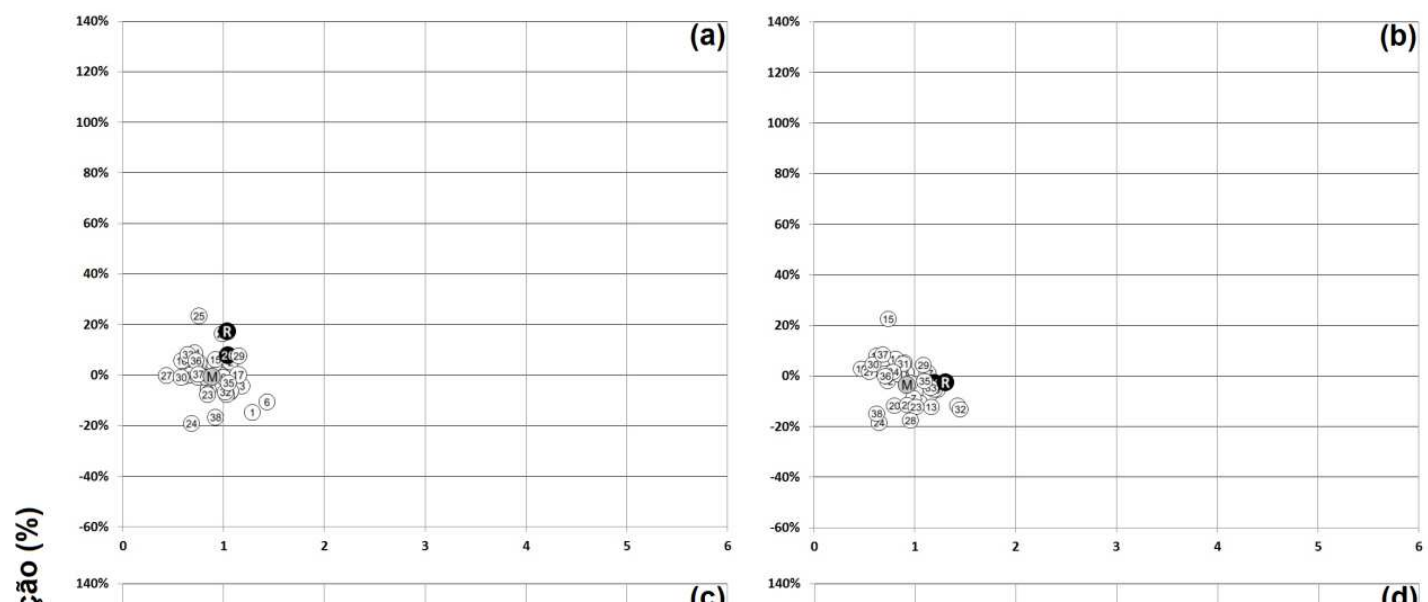

(c)
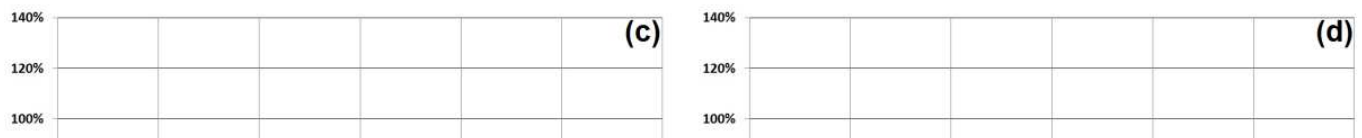

10

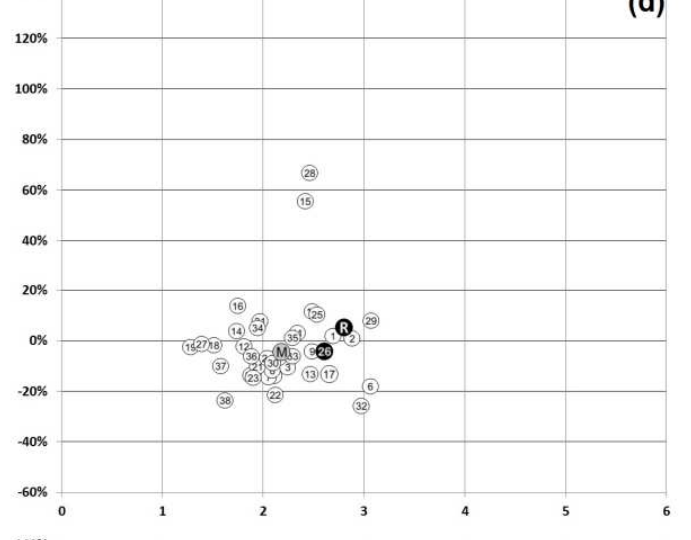

(e)
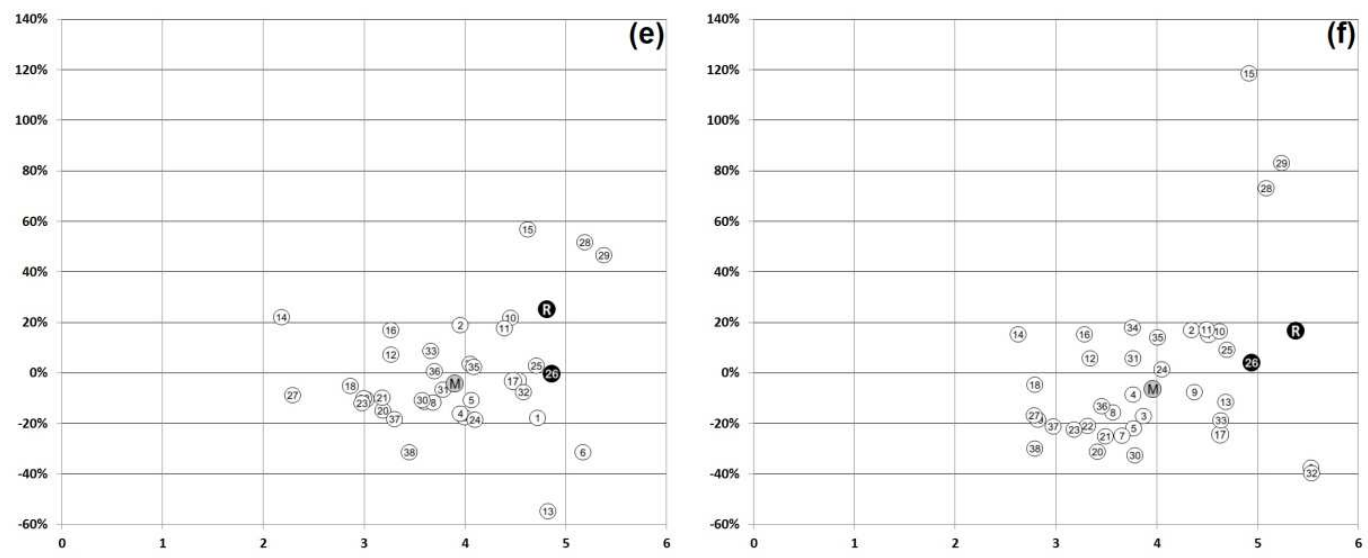

Diferença de Temperatura $\left({ }^{\circ} \mathrm{C}\right)$

Figura 10 - Distribuição da porcentagem da diferença de precipitação pela diferença de temperatura entre as três "fatias de tempo" futuras (cenário RCP8.5) e o período histórico sobre o NNEB (esquerda) e SNEB (direita) apresentada pelos modelos do CMIP5 (números de 1 a 38 - Tabela 2 -, em destaque o modelo HadGEM2-ES, número 26), a média entre eles (M) e o modelo RAMS (R): (a,b) curto prazo, (c,d) médio prazo e (e,f) longo prazo.

No tocante às projeções para a metade do século (Figuras 10c e 10d sobre o NNEB e SNEB, respectivamente), é observado um maior espalhamento por parte dos modelos, porém a média entre eles manteve-se próximo do valor nulo para a mudança de precipitação. Este espalhamento se concentra principalmente no sinal de acréscimo do sinal, chegando à aproximadamente $50 \%$ e $70 \%$ (IPSL-CM5A-LR, número 28) sobre o NNEB e SNEB, respectivamente, enquanto os modelos CSIRO-Mk3-6-0 (número 13). MIROC-ESM-CHEM (número 32) foram os que apresentaram maior redução em percentual sobre o NNEB e SNEB, respectivamente. Nas duas subregiões o modelo RAMS6.0 apresenta acréscimo, enquanto o HadGEM2-ES indica atenuação do padrão de precipitação a médio prazo. Já para a temperatura, os modelos projetam um 
maior aumento desta variável, comparado à "fatia de tempo" anterior, com a média deles ultrapassando os $2^{\circ} \mathrm{C}$. Sobre o NNEB, o espalhamento se dá entre $1^{\circ} \mathrm{C}$ (inm-cm4, número 27) e $3^{\circ} \mathrm{C}$ (CanESM2 e IPSL-CM5A-MR, números 6 e 29, respectivamente), enquanto que sobre o $\mathrm{SNEB}$ os valores ultrapassam os $3^{\circ}$ (CanESM2 e IPSL-CM5A-MR). Os modelos RAMS6.0 e HadGEM2-ES apresentaram aquecimento acima de $2,5^{\circ} \mathrm{C}$.

Nas projeções para o final do século, considerável espalhamento entre os sinais dos modelos são verificados. Alguns modelos apresentam espalhamento de precipitação marcando -60\% sobre o NNEB (CSIRO-Mk3-6-0, número 13) e de $-40 \%$ sobre o SNEB (MIROC-ESM-CHEM), outros apresentam valores de $60 \%$ e de $120 \%$ (FGOALS-s2, número 15) sobre o NNEB e SNEB, respectivamente. O modelo RAMS projeta um aumento em torno de $20 \%$ em ambas as sub-regiões, enquanto o HadGEM2-ES um valor próximo do nulo. Para a temperatura, os modelos apresentaram um aquecimento para o final do século entre aproximadamente $2,5^{\circ} \mathrm{C}$ (FGOALS-g2, número 14) e (IPSL-CM5A-MR, número 29, respectivamente). Os modelos RAMS6.0 e HadGEM2-ES apresentaram um aquecimento médio próximo de $5^{\circ} \mathrm{C}$ sobre o NNEB. Já na parte sul do NEB, o modelo RAMS ultrapassa os $5^{\circ} \mathrm{C}$.

\section{CONCLUSÕES}

Neste trabalho foram apresentados resultados referentes ao uso da técnica de downscaling dinâmico para projeções de mudanças climáticas sobre duas sub-regiões do Nordeste Brasileiro: Norte (NNEB) e Sul (SNEB). O Modelo Climático Regional (MCR) RAMS6.0 foi forçado pelas análises do Modelo Climático Global (MCG) HadGEM2-ES, um modelo participante do CMIP5, como proposto pelo CORDEX. Foram realizadas análises da precipitação e temperatura no período histórico (clima presente, de 1986 até 2005) e em três "fatias de tempo" futuras: curto (de 2016 até 2035) médio (de 2046 até 2065) e longo prazo (de 2080 até 2099), sob o cenário de emissão de gases de efeito estufa RCP8.5. Também foram comparadas as projeções do RAMS6.0 e do HadGEM2-ES com as disponibilizadas pelos modelos do CMIP5.

Para o período histórico, em geral, tanto o HadGEM2-ES, quanto o RAMS6.0 conseguiram reproduzir características do clima recente, incluindo distribuição sazonal e, em alguns casos, padrões espaciais de precipitação e temperatura. Os modelos apresentaram basicamente viés úmido (seco) na estação chuvosa (seca) e frio durante o ano todo em ambas as regiões de estudo. Pode-se perceber que o uso do modelo regional permite uma melhor representação de alguns aspectos do clima observado e a correção de alguns erros apresentados pelo global (no caso deste trabalho, isto se verificou principalmente na distribuição espacial das variáveis, principalmente temperatura, na fase do ciclo anual de precipitação e na redução do viés frio dos dados de grande escala). A melhor representação da distribuição espacial da precipitação e, principalmente da temperatura, está relacionada com maior resolução do MCR, o que introduz uma melhoria na representação da topografia e da linha costeira.

No entanto, alguns erros do MCG são amplificados e erros sistemáticos inerentes ao próprio modelo regional são introduzidos (como a amplificação do viés úmido, principalmente na estação chuvosa, já presente na simulação do $\mathrm{MCG}$, mas é maior na simulação pelo MCR). As características do esquema de parametrização de convecção do MCR (KainFritsch), o qual é baseado na convergência do fluxo de umidade, podem ser a causa para o sinal superestimado da precipitação sobre o NNEB, conforme foi também observado por Silveira et al. $(2011,2014)$ para simulações de previsão do tempo utilizando o RAMS6.0 para o estado do Ceará.

Para o clima futuro, alguns padrões são projetados por ambos os modelos em ambas as sub-regiões, como a redução de precipitação no inverno e primavera austral em médio e longo prazo (exceto o HadGEM2-ES sobre o SNEB em médio prazo), o aumento de precipitação nos meses de verão nos três períodos do clima futuro analisado (exceto o HadGEM2-ES sobre o NNEB em médio prazo) e aumento da temperatura durante o século XXI, principalmente nas regiões mais afastadas da costa. $\mathrm{O}$ aquecimento esperado sobre o NEB também foi encontrado em outros trabalhos de mudanças climáticas que utilizaram a técnica de downscaling dinâmico, como em (Marengo et al. (2010) e Reboita et al. (2014)), sendo esta projeção sumarizada no trabalho de Solman (2013).

Essas projeções também foram comparadas com as de outras advindas de MCGs participantes do CMIP5. Quanto à projeção de temperatura, o modelo RAMS6.0 simulou aumentos próximos aos do HadGEM2-ES e ambos se mostraram entre os modelos que projetam maior aquecimento em ambas as regiões. Quanto à precipitação, o MCR simulou um crescimento desta variável ao longo do século, enquanto o global que o forçou, projetou percentuais de redução (exceto em curto prazo sobre o NNEB e em longo prazo sobre o SNEB). Todos os modelos estudados projetaram aquecimento para a região do NEB durante o século 21, porém, quanto à precipitação, ainda permanece uma divergência por parte dos modelos do CMIP5, que deve ser alvo de estudo para tentar entender as incertezas relacionadas a esta variável.

Para trabalhos futuros, investigações utilizando as simulações do MCR estão sendo feitas a fim de se avaliar possíveis mudanças na ocorrência de fenômenos extremos. Os resultados produzidos também estão sendo disponibilizados para estudos de impactos em setores como recursos hídricos e agricultura. Porém, como citado por Solman et al. (2013), 
é necessário aplicar um método de correção de viés antes de aplicar as simulações do modelo regional para qualquer estudo de impacto. Torna-se importante estudar outros campos, como fluxos de radiação de onda curta e longa, bem como, fluxos de calor latente e sensível para o entendimento dos erros de viés na temperatura e precipitação por parte dos modelos.

\section{AGRADECIMENTOS}

Ao Instituto Nacional do Semiárido (INSA) e ao Conselho Nacional de Desenvolvimento Científico e Tecnológico (CNPq), pela concessão de bolsa ao primeiro autor. Este trabalho faz parte de um conjunto de estudos de mudanças climáticas e avaliação de impactos desenvolvidos na Universidade Estadual do Ceará (UECE) em parceria com o INSA, por meio do Acordo de Cooperação Técnica $\mathrm{N}^{\circ}$ 02/2012. O financiamento deste trabalho se deu via CNPq e Fundação Cearense de Apoio ao Desenvolvimento Científico e Tecnológico através, respectivamente, dos projetos MOREA(Modelagem Climática Regional - Downscaling - e suas Aplicações em Energias Renováveis, Edital 05/2010, Processo 555675/2010-6) e MUVUCA (Mudanças Climáticas, Variabilidade Climáticas e seus Impactos no Semiárido: Recursos Hídricos, Energia Renováveis, Ambiente e Agricultura, Edital 09/2010, PRONEM). O primeiro autor também agradece a todos os parceiros da Fundação Cearense de Meteorologia e Recursos Hídricos (FUNCEME).

\section{REFERÊNCIAS BIBLIOGRÁFICAS}

ALVES, L. M., MARENGO, J. Assessment of regional seasonal predictability using the PRECIS regional climate modeling system over South America. Theoretical and Applied Climatology. v. 100, p. 337-350. 2010.

BOULANGER, J.-P., BRASSEUR, G., CARRIL, A. F., CASTRO, M., DEGALLIER, N., EREÑO, C., Le TREUT, H., MARENGO, J. A., MENENDEZ, C. G., NUÑEZ, M. N., PENALBA, O. C., ROLLA, A. L., RUSTICUCCI, M., TERRA, R. A Europe-South America network for climate change assessment and impact studies. Climatic Change. v. 98. p.307-3019. 2010.

CHEN, C., COTTON, W. R. A one-dimensional simulation of the stratocumulus-capped mixed layer.Boundary-Layer Meteorology. v. 25, n. 3, p. 289-321. 1983.

COLLINS, W. J., BELLOUIN, N., DOUTRIAX-BOUCHER, M., GEDNEY, N., HINTON, T., JONES, C. D., LIDDICOAT, S., MARTIN, G., O'CONNOR, F., RAE, J., SENIOR, C., TOTTERDELL, I., WOODWARD, S., REICHLER, T., KIM, J. Evaluation of the HadGEM2 model. Hadley Centre technical note $74.47 \mathrm{pp} .2008$
COTTON, W. E., PIELKE, R. A., WALKO, R. L., LISTON, G. E., TREMBACK, C. J., JANG, H., MCANNELLY, R. L., HARRINGTON, J.-Y., NICHOLLS, M. E., CARRIO, G. G., McFADDEN, J. P., RAMS 2001: current status and future directions. Meteorology and Atmospheric Physics. v. 82, p. 5-29. 2003.

FRITSCH, J. M., CHAPPELL, C., Numerical simulation of convectively driven pressure system. Part I: convective parameterization. Journal of the Atmospheric Sciences. v.37, p. 1722-1733. 1980.

GIORGI, F., JONES, C., ASRAR, G. R. Addressing climate information needs at the regional level: the CORDEX framework. WMO Bulletin. v. 3, n. 58, p.175-183. 2009

GRANT, A. L. M. Cloud-base fluxes in the cumulus-capped boundary layer. Quarterly Journal of the Royal Meteorological Society. v. 127. p.407-421. 2001.

GREGORY, D., ROWNTREE, P. R. A mass flux convection scheme with representation of cloud ensemble characteristics and stability dependent closure. Monthly Weather Review. v. 118, p. 1483-1506. 1990.

INTERGOVERNMENTAL PANEL ON CLIMATE CHANGE (IPCC): Climate Change 2007: The Physical Science Basis - Working Group I. Contribution to the IPCC Fourth Assessment Report. Brussels. February, 2007.

INTERGOVERNMENTAL PANEL ON CLIMATE CHANGE (IPCC): Climate Change 2013: The Physical Science Basis. Contribution of Working Group I to the Fifth Assessment Report of the Intergovernmental Panel on Climate Change [Stocker, T.F., D. Qin, G.-K. Plattner, M. Tignor, S.K. Allen, J. Boschung, A. Nauels, Y. Xia, V. Bex and P.M. Midgley (eds.)]. Cambridge University Press, Cambridge, United Kingdom and New York, NY, USA, 1535 pp. 2013.

KAIN, J., FRITSCH, J. M. A one-dimensional entraining/ detraining plume model and its application in convection parameterization.Journal of the Atmospheric Sciences. v. 47, n. 23, p. 2784-2802. 1990.

KAYANO, M. T.; ANDREOLI, R. V. Clima da Região Nordeste do Brasil. Tempo e Clima no Brasil. [CAVALCANTI, I. F. A., FERREIRA, N. J., SILVA, M. G. A. J., DIAS, M. A. F. S. (org.)]. Cap.14. p.213-233. Oficina de Textos. São Paulo. 2009.

KOUSKY, V. E. Frontal influences on Northeast Brazil. Monthly Weather Review. v. 107, n. 9, p. 1140-1153. 1979.

MARENGO, J. A., JONES, R., ALVES, L. M., VALVERDE, M. C. Future change of temperature and precipitation extremes in South America as derived from the PRECIS regional climate modeling system. International Journal of Climatology. v. 29. p. 2241-2255. 2009. 
MARENGO, J. A., AMBRIZZI, T., da ROCHA, R. P., ALVES, L. M., CUADRA, S. V., VALVERDE, M. C., TORRES, R. R., SANTOS, D. C., FERRAZ, S. E. T. Future change of climate in South America in the late twenty-first century: intercomparison of scenarios from three regional climate models. Climate Dynamics. v. 35, p. 1073-1097. 2010.

MARTiN, G. M., BELlOUIN, N., COLlins, W. J., CULVERWELL, I. D., HALLORAN, P. R., HARDIMAN, S. C., HINTON, T. J., JONES, C. D., McDONALD, R. E., McLAREN, A. J., O'CONNOR, F. M., ROBERTS, M. J., RODRIGUEZ, J. M., WOODWARD, S., BEST, M. J., BROOKS, M. E., BROWN, A. R., BUTCHART, N., DEARDEN, C., DERBYSHIRE, S. H., DHARSSI, I., DOUTRIAUX-BOUCHER, M., EDWARDS, J. M., FALLON, P. D., GEDNEY, N., GRAY, L. J., HEWITT, H. T., HOBSON, M., HUDDLESTON, M. R., HUGHES, J., INESON, S., INGRAM, W. J., JAMES, P. M., JOHNS, T. C., JOHNSON, C. E., MILTON, S. F., RAE, J. G. L., RIDLEY, J. K., SELLAR, A., SENIOR, C. A., TOTTERDELL, I. J., VERHOEF, A., VIDALE, P. L., WILTSHIRE, A. The HadGEM2 family of Met Office Unified Model climate configurations. Geoscientific Model Development. v. 4. p. 723-757. 2011.

MELLOR, G. L., YAMADA, T. Hierarchy of turbulence closure models for planetary boundary-layers. Journal of the Atmospheric Sciences. v. 31, n. 7, p. 1791-1806. 1974.

MELLOR, G. L., YAMADA, T. Development of a turbulence closure-model for geophysical fluid problems.Reviews of Geophysics. v. 20, n. 4, p. 851-875. 1982.

MET OFFICE. Disponível em $<\mathbf{h t t p}$ ://www.metoffice.gov. uk/research/modelling-system/unified-model/weatherforecasting $>$. 2014.

MOSS, R. H., EDMONDS, J.A., HIBBARD, K.A., MANNING, M. R., ROSE, S. K., van VUUREN, D. P., CARTER, T. R., EMORI, S., KAINUMA, M., KRAM, T., MEEHL, G. A., MITCHELL, J. F. B., NAKICENOVIC, N., RIAHI, K., SMITH, S. J., STOUFFER, R. J., THOMSON, A. M., WEYANT, J. P., WILBANKS, T. J. The next generation of scenarios for climate change research and assessment. Nature. v. 463, n. 11, p. 747-756. February. 2010.

NAKICENOVIC, N., ALCAMO, J., DAVIS, G., deVRIES, B., FENHANN J., GAFFIN, S., GREGORY, A., GRÜBLER, A. Emission scenarios - Special Report of Working Group III of the IPCC. 595pp. Geneva, and Cambridge University Press, Cambridge. 2010.

NCDC NOAA. Disponível em <http://www.ncdc.noaa.gov/ data-access/model-data/model-datasets/global-forecastsystem-gfs>. 2014.

NEW, M., HULME, M., JONES, P. D. Representing TwentiethCentury space-time climate variability. Part 1: Development of a 1961-1990 mean monthly terrestrial climatology. Journal of Climate. v. 12, p. 829-856. 1999.

NEW, M., HULME, M., JONES, P. D. Representing TwentiethCentury space-time climate. Part 2: Development of 190196 monthly grids of terrestrial surface climate. Journal of Climate. v. 13. p. 2217-2238. 2000.

NOBRE, P., MOURA,A. D., SUN, L. Dynamical downscaling of seasonal climate prediction over Nordeste Brazil with ECHAM3 and NCEP'S Regional Spectral Model at IRI. Bulletin of American Meteorological Society, v. 82, p. 2787-2796, Boston. 2001

PESQUERO, J. F., CHOU, S. C., NOBRE, C. A., MARENGO, J. A. Climate Downscaling over South America for 19611970 using the Eta Model. Theoretical and Applied Climatology. v. 99. p. 75-93. 2010.

PIELKE, R.A., COTTON, W. R., WALKO, R. L., TREMBACK, C. J., LYONS, W. A., GRASSO, L. D., NICHOLLS, M. E., MORAN, M. D., WESLEY, D. A., LEE, T. J., COPELAND, M. E. A comprehensive meteorological modeling system RAMS. Meteorology and Atmospheric Physics. v. 49, n. 1-4, p. 69-91.1992.

PINTO, L. I. C., COSTA, M. H., LIMA, F. Z., DINIZ, L. M. F., SEDIYAMA, G., PRUSKI, F. F. Comparação de produtos de precipitação para a América do Sul. Revista Brasileira de Meteorologia. v. 24, n. 4, p. 461-472. 2009.

PITMAN, A. J., NARISMA, G. T., McANENEY, J. The impact of climate change on the risk of forest and grassland fires in Australia. Climatic Change, v. 84, p. 383-401. 2007.

RAUSCHER, S. A., SETH, A., LIEBMANN, B., QIAN, J.-H., CAMARGO, S. J. Regional climate model-simulated timing and character of seasonal rains in South America. Monthly Weather Review, v. 135, p. 2642-2657. 2007.

RCP Database. Disponível em: <http://www.iiasa.ac.at/webapps/tnt/RcpDb>. 2009.

REBOITA, M. S., da ROCHA, R. P., DIAS, C. G., YNOUE, R. Y. Climate projections for South America: RegCM3 driven by HadCM3 and ECHAM5. Advances in Meteorology. http://dx.doi.org/10.1155/2014/376738. 2014.

SALES, D. C. Simulações de downscaling dinâmico do clima presente sobre as Américas Tropicais. 2011. 177 f. Dissertação (mestrado) - Curso de Mestrado Acadêmico em Ciências Físicas Aplicadas, Universidade Estadual do Ceará, Fortaleza. 2011.

SALES, F., XUE, Y. Assessing the dynamic-downscaling ability over South America using the intensity-scale verification technique. International Journal of Climatology, v. 31, p. 1205-1221. 2011.

SETH, A., RAUSCHER, S. A., CAMARGO, S. J., QIAN, J.H., PAL, J. S. RegCM3 regional climatologies for South America using reanalysis and ECHAM global model driving 
fields. Climate Dynamics. v. 28, p. 461-480. 2007.

SILVEIRA, C. S., COSTA, A. A., COUTINHO, M. M., SOUZA FILHO, F. A., VASCONCELOS JÚNIOR, F. C., NORONHA, A. W. Verificação das previsões de tempo para precipitação usando ensemble regional para o estado do Ceará em 2009. Revista Brasileira de Meteorologia. v. 26. n. 4. São Paulo. 2011.

SILVEIRA, C. S., COUTINHO, M. M., COSTA, A. A., de MARIA, P. H. S. Previsão de tempo por conjuntos para a região do Nordeste do Brasil. Revista Brasileira de Meteorologia. v. 29. n. 3. São Paulo. 2014.

SOLMAN, S. A. Regional climate modeling over South America: A review. Advances in Meteorology. http://dx.doi. org/10.1155/2013/504357. 2013.

SOLMAN, S. A., SANCHEZ, E., SAMUELSSON, P., da ROCHA, R. P., LI, L., MARENGO, J., PESSACG, N. L., REMEDIO, A. R. C., CHOU, S. C., BERBERY, H., Le TREUT, H., CASTRO, M., JACOB, D. Evaluation of an ensemble of regional climate model simulations over South America driven by ERA-Interim reanalysis: model performance and uncertainties. Climate Dynamics. v, 41. p. 1139-1157. 2013.

SUN, L., MONCUNILL, D., HUILAN, L., MOURA, A. D., FILHO, F. A S. Climate downscaling over Nordeste Brazil using NCEP RSM97.Journal of Climate, v. 18, n. 4, p. 551-567, Boston. 2005.

SUN, L., MONCUNILL, D., HUILAN, L., MOURA, A. D., FILHO, F. A. S., ZEBIAK, E. An operational dynamical downscaling prediction system for Nordeste Brazil and the 2002-04 real time forecast evaluation. Journal of Climate, v. 19, n. 10, p. 1990-2007, 2006.
TAYLOR, E. K., STOUFFER, R. J., MEEHL, G. A. An overview of CMIP5 and the experiment design. Bulletin of American Meteorological Society, v. 93, p. 485-498. April, 2012.

WALKO, R. L., COTTON, W. R., MEYERS, M. P., HARRINGTON, J. Y. New RAMS cloud microphysics parameterization Part I: the single-moment scheme. Atmospheric Research, Elsevier. v. 38, n. 1-4, p. 29-62. 1995.

WALKO, R. L., BAND, L. E., BARON, J., KITTEL, T. G. F., LAMMERS, R., LEE, T. J., OJIMA, D., PIELKE, R. A., TAYLOR, C., TAGUE, C., TREMBACK, C. J., VIDALE, P. L. Coupled atmosphere-biophysics-hydrology models for environmental modeling. Journal of Applied Meteorology, v. 39, n. 6, p. 931-944. 2000.

WANG, Y., LEUNG, L. R., McGREGOR, J. L., LEE, D.-K., WANG, W.-C., DING, Y., KIMURA, F. Regional climate modeling: progress, challenges, and, prospects. Journal of the Meteorological Society of Japan. v. 82, n. 6, p. 15991628. 2004.

WCRP (World Climate Research Programme), Evaluating and Improving Regional Climate Projections.Workshop Report, Toulose, France, 11-13 February 2009, WCRP Informal Report $<$ http://wcrp.ipsl.jussieu.fr/Workshops/ Downscaling/Documents/CORDEX_Workshop09.pdf $>$ No. 5/2009. 2009.

WILKS, D. S. Statistical methods in the Atmospheric Sciences ( $3^{\text {rd }}$ Edition). Academic Press, NY, 676pp. 2011. 